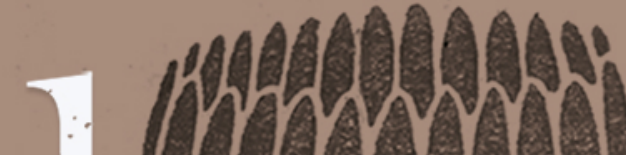

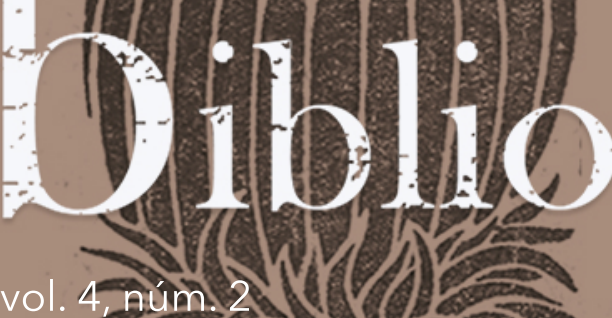

vol. 4, Aum?2

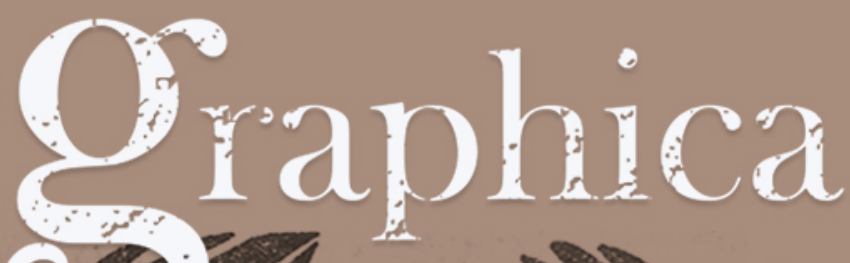

segubdo-semestre 2021 s.

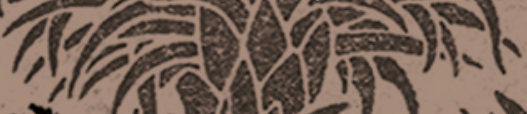
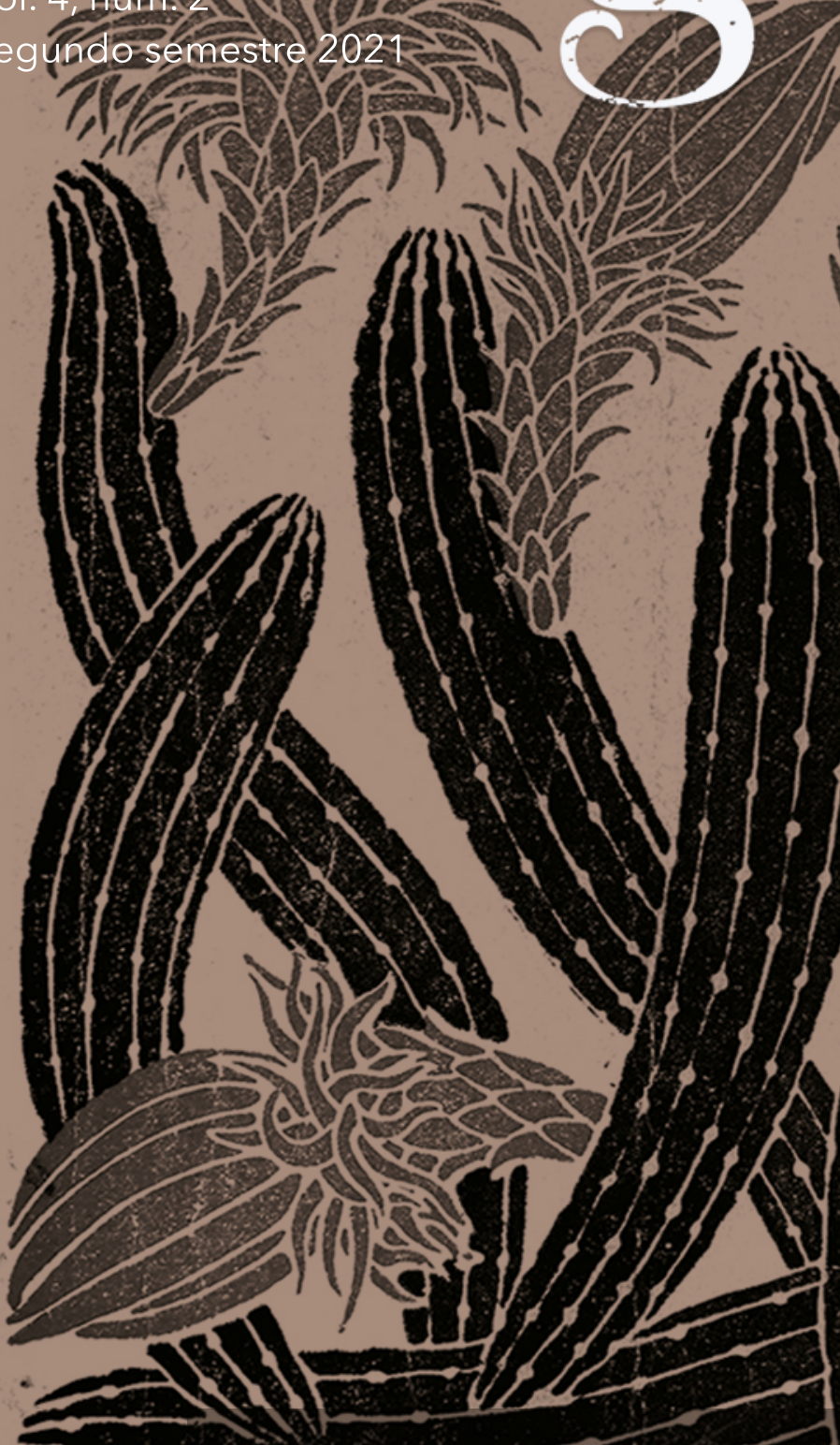

ISSN $2594-178 X$
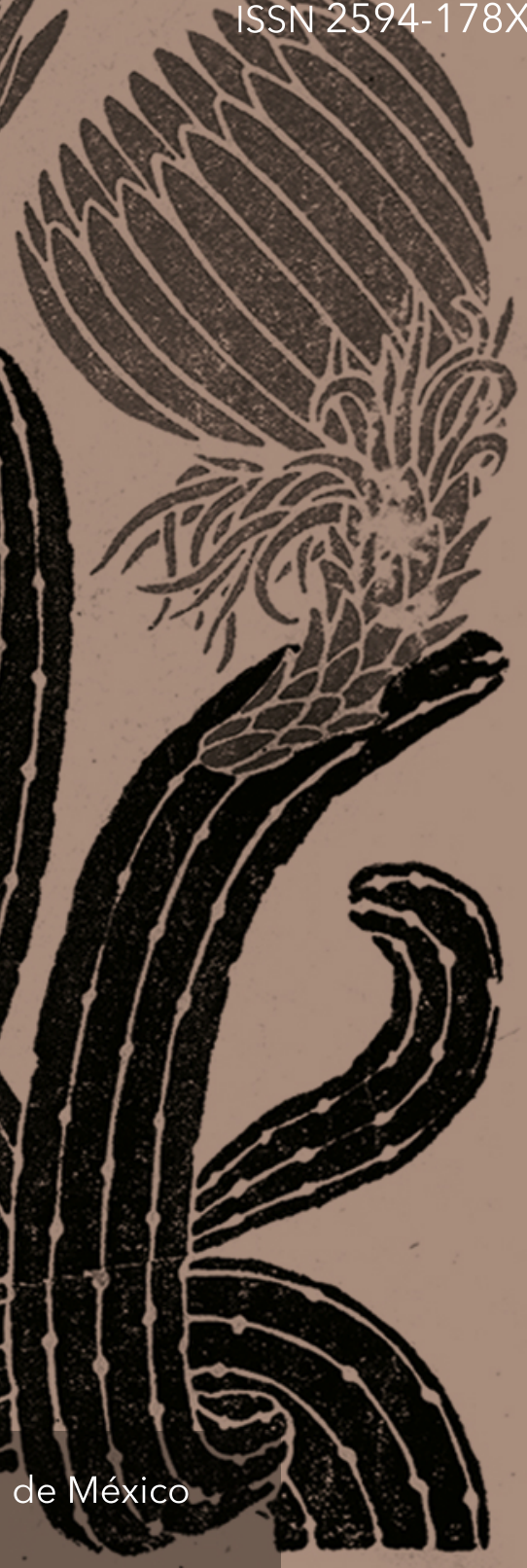


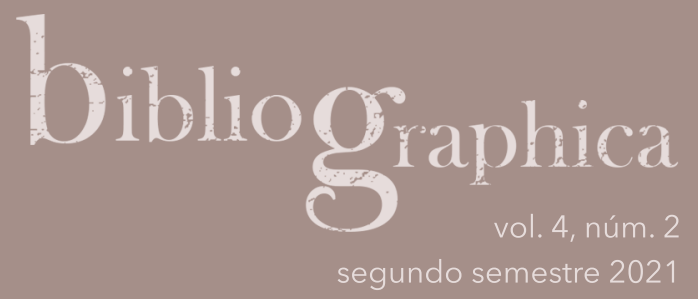

\section{Los libros de la Tipografía Nacional: cultura visual y escrita del liberacionismo en Guatemala, 1954-1957}

The Books of the Tipografia Nacional:

Visual and Written Culture of the Liberation

Movement in Guatemala, 1954-1957

\section{Juan Carlos Vázquez Medeles}

Universidad Nacional Autónoma de México,

Centro de Investigaciones sobre América Latina y el Caribe,

Ciudad de México. México

vazquezjc@gmail.com

ORCID: https://orcid.org/0000-0003-0673-8578

Recepción: 08.03.2021 / Aceptación: 01.06.2021

DoI: https://doi.org/10.22201/iib.2594178xe.2021.2.103 
Resumen

Palabras clave

Abstract

Keywords
Este trabajo presenta el repertorio bibliográfico impreso en los talleres de la Tipografía Nacional de Guatemala, a cargo de la Secretaría de Divulgación, Cultura y Turismo de la Presidencia de la República, entre 1954 y 1957. El objetivo es exponerlo como parte de la cultura escrita del liberacionismo, resaltar sus características y advertir la función que tuvo durante el gobierno de Carlos Castillo Armas. Su estudio resultó en la clasificación en dos rubros, los cuales permiten señalar sus objetivos como herramientas discursivas -el primero en la función gubernativa y el otro en calidad de propaganda- que fueron el sostén jurídico y simbólico de dicho régimen, y la estructuración del anticomunismo en Guatemala.

Tipografía Nacional; Carlos Castillo Armas; liberacionismo; anticomunismo; Guatemala.

This work presents the bibliographic repertoire printed in the workshops of the Tipografía Nacional of Guatemala, an institution in charge of running the Office of Dissemination, Culture and Tourism of the Presidency of the Republic, between 1954 and 1957. The primary purpose here is to exhibit the publications as part of the liberation movement's written culture, to highlight its features, and note the role it played during Carlos Castillo Armas' administration. The study resulted in a two-category classification of these materials that made possible to pinpoint the repertoire's objectives as discursive tools -the first in the gubernatorial function and the other as propaganda-, which were the legal and symbolic support of said regime, and the formation of anti-communism in Guatemala.

Tipografía Nacional; Carlos Castillo Armas; liberation movement; anti-communism; Guatemala. 


\section{Introducción ${ }^{1}$}

La cultura escrita que se generó en Guatemala después del ascenso al poder de los liberacionistas, en junio de 1954, respondió a los intereses políticos del nuevo gobierno encabezado por el coronel Carlos Castillo Armas. En este proceso, la Secretaría de Divulgación, Cultura y Turismo de la Presidencia de la República (SDCYT) y la Tipografía Nacional imprimieron diversas obras bajo este carácter. Para analizarlas en conjunto es necesario establecer que esta última es la editorial oficial desde finales del siglo XIX hasta nuestros días. ${ }^{2}$ Su objetivo es comunicar los logros y la política de los gobiernos en turno, además de difundir la literatura e historia del país.

Durante los gobiernos revolucionarios se enfatizó la difusión de la literatura (1945-1954). En 1949 fue adquirida la imprenta del editor de origen catalán Bartolomeu Costa-Amic, quien se trasladó de México a Guatemala con cuatro de sus operarios para dirigir los talleres. ${ }^{3}$ El Ministerio de Educación también creó en esta dependencia la Editorial José de Pineda Ibarra, a cargo de Julio Estrada de la Hoz y posteriormente de Edelberto Torres. Se instituyeron series como la Biblioteca 20 de Octubre, Los de Ayer, Los Contemporáneos y el premio 15 de Septiembre, que llegaron a producir cerca de 200 títulos. Este empeño de la Tipografía Nacional, a cargo de Carlos González Orellana, incluyó la creación de varias publicaciones periódicas, por ejemplo la Revista Alegría, Revista del Maestro y el proyecto cultural de Luis Cardoza y Aragón, la Revista de Guatemala.

Tras el triunfo contrarrevolucionario, quedó desarticulado el esfuerzo previo. ${ }^{4}$ De inmediato, la nueva burocracia se adaptó al funcionamiento de los medios técnicos para imprimir libros que ponderaron las acciones y la ideología de los liberacionistas. En este proceso desapareció la Secretaría de Propaganda y Divulgación de la Presidencia de la República, a cargo del capitán Rodolfo

\footnotetext{
1 Juan Carlos Vázquez Medeles. UNAM. Programa de Becas Posdoctorales en la UNAM, Becario del Centro de Investigaciones sobre América Latina y el Caribe, asesorado por el doctor Mario Vázquez Olivera.

${ }^{2}$ Durante su gestión, el presidente José María Reyna Barrios (1892-1829) adquirió una imprenta para promover el desarrollo de su gobierno. En 1922, el general José María Orellana inauguró la sede que continúa en labores.

${ }^{3}$ Arturo Taracena, Guatemala, la República Española y el Gobierno Vasco en el exilio (19441954) (México: El Colegio de México, 2017), 332-333.

${ }^{4}$ El 1o. de julio de 1954 asumió la dirección el capitán Enrique Castillo, 10 días después lo sustituyó el coronel Luis Alberto Ruano de León. Con Castillo Armas en la presidencia, fue designado Clodomiro Barillas Araúz.
} 
González Centeno, para dar paso a la SDCy ${ }^{5}$ y así establecer un nuevo proyecto cultural y editorial a cargo de Enrique Salazar Liekens. ${ }^{6}$

La función de la Tipografía Nacional implicó la elaboración de "trabajos tipográficos destinados al servicio administrativo de las dependencias del Gobierno, tales como formularios, libros, folletos y otros que incluyen hasta la fabricación de sobres",7 y se imprimió una gran variedad de materiales escritos, entre los cuales se encuentran publicaciones periódicas, registro de la obra y función de dicho gobierno, y ensayos u obras literarias de distinta índole.

El interés de mostrar los textos publicados en la Tipografía Nacional es presentarlos como parte de la cultura escrita del liberacionismo, destacar sus características y señalar su función durante la administración de Carlos Castillo Armas. Por sus particularidades, fueron divididos en dos rubros que, en general, irrumpen la retórica de los regímenes revolucionarios y delimitan puntos de intersección con el nuevo marco jurídico, pues tienen una existencia conexa con los decretos que se desarrollaron en esos meses. El primer rubro corresponde a textos que son producto de esta administración; son, en sí, el mecanismo político y jurídico con el cual construyeron el nuevo Estado. El segundo está conformado por publicaciones ceñidas al ideario anticomunista de los liberacionistas; concebidas como propaganda contra el comunismo, expresan su imaginario y quehacer histórico.

Para recopilar los materiales se llevó a cabo una búsqueda en diferentes acervos bibliográficos, tanto en México como en Guatemala. De gran utilidad fueron las bibliotecas de El Colegio de México, la Tipografía Nacional y el Centro de Investigaciones Regionales de Mesoamérica, lugar donde también fue valioso el contenido del Archivo Histórico del Fondo Eduardo Taracena de la Cerda.

En cuanto a las publicaciones periódicas ${ }^{8}$ y la folletería informativa que se produjo, pese a la importancia de su contenido y las cualidades de cada una

\footnotetext{
${ }^{5}$ Decreto 224, del 4 de febrero de 1955, de la Recopilación de Leyes, t. 73, 206.

${ }^{6}$ Salazar Liekens ocupó el cargo de subsecretario del Ministerio de Comunicaciones y Obras Públicas; también fue, desde el 23 de julio, secretario de la SDCyT. Su padre, Enrique Salazar Gatica, era miembro de la junta directiva del Crédito Hipotecario Nacional y su tío, Carlos Salazar Gatica, ministro de Relaciones Exteriores.

${ }_{7}^{7}$ Ministerio de Gobernación, Memoria de las labores del ramo de Gobernación del 2 de julio de 1954 al 31 de diciembre de 1955 (Guatemala: Tipografía Nacional, 1957), 15.

${ }^{8}$ En el periodo estudiado se publicaron El Guatemalteco. Diario Oficial de la República de Guatemala, Informador Gráfico, Anales de la Sociedad de Geografía e Historia de Guatemala, La Voz de Guatemala, Boletín de la Radio Nacional TGW, Orden. Revista de la Policía Nacional, Revista Agrícola, El Campesino y Revista del Colegio de Infantes.
} 
de ellas, no nos detendremos en su análisis. En primer lugar, por la imposibilidad de acceder a las colecciones, que son inexistentes o segmentadas. En segundo, porque el objetivo de este trabajo está enfocado en los materiales que son presentados como objeto-libro y permitieron la circulación de ideas y representaciones. Debido a su incidencia en el espacio social, se ubicaron como objetos simbólicos y materiales representantes de una visión del mundo.

La concepción de los términos utilizados -como el de comunismo-en las obras expuestas permite afirmar que son formas en que se transcribe la realidad y se crea una representación de la misma. En este sentido, para el análisis del papel fundamental de la ideología se consideraron dos conceptos que aportó Edmond Cros. El primero de ellos, el ideologema, interactúa como discurso social que se expresa en una obra literaria, pronuncia la conciencia social y colectiva, en la que se impone con distintos recursos como la recurrencia y modifica su campo semántico, se le agregan valores que reformulan su significado original y se presentan de manera específica en el texto con la integración de un sistema ideológico. ${ }^{9}$ El segundo, el ideosema, se refiere al ensamble de prácticas discursivas y sociales que se articulan en torno al texto, reordenan el material lingüístico y cultural, y actúa como productor de sentido. ${ }^{10}$ Esto permitió estructurar nociones de una praxis política a partir de la moral y ética cristiana, además de una nueva práctica que se ciñó a la administración pública.

\section{Rubro Gubernativo}

En este primer rubro se presentan cuatro tipos de obras relacionadas con la administración del gobierno de Carlos Castillo Armas: a) Legislativos; b) Discursos; c) Administrativos; d) Otros. Inicia con el trabajo desarrollado durante la cuarta y definitiva Junta de Gobierno, ${ }^{11}$ como parte del ordenamiento del nuevo marco político e institucional de los contrarrevolucionarios.

\footnotetext{
${ }^{9}$ Edmond Cros, La sociocrítica (Madrid: Arco Libros / La Muralla, 2009), 211-216.

${ }^{10}$ Edmond Cros, Ideosemas y morfogénesis del texto. Literaturas española e hispanoamericana (Fráncfort: Vervuert Verlag, 1992), 7-19.

${ }^{11}$ Conformaron la Junta de Gobierno el coronel Carlos Castillo Armas, como presidente, y en calidad de vocales el coronel Elfego Hernán Monzón Aguirre y el mayor Enrique Trinidad Oliva Quintana.
} 


\section{a) Legislativos}

Desde la instauración de la Junta de Gobierno, estos materiales se produjeron con el nuevo personal de los talleres de la Tipografía Nacional. ${ }^{12}$ Fueron parte del proceso de desmantelamiento del régimen democrático anterior y de la implementación de nuevos dispositivos y normativas de convivencia. Cinco semanas después de ser conformada dicha junta, se estableció un Estatuto Político, para conferirle un marco legal y político. Con ello, se derogó la Constitución de 1945 y se le concedieron los poderes legislativos y ejecutivos, la libertad para nombrar funcionarios públicos y la administración de los recursos económicos del país. Fue la formalización de lo que ya ejercía la Junta desde su imposición. Ante la importancia de este documento, se imprimieron 15 mil ejemplares.

En las principales medidas adoptadas se hizo patente el fervor ideológico que luego se convirtió en la persecución de sus adversarios, considerados un riesgo para su ideal de patria. En este sentido, el Decreto núm. 23 instituyó el Comité de Defensa Nacional Contra el Comunismo (CDNCC), ${ }^{13}$ organismo que también respondió a las funciones de la Agencia Central de Inteligencia (CIA) de Estados Unidos, a través del programa conocido como PBHISTORY, para convertirlo en "una fuente auténtica de información sobre la penetración comunista en el Hemisferio Occidental". 14

Además, con la emisión del Decreto núm. 59 del 29 de agosto, establecieron la Ley Preventiva Penal contra el Comunismo, con la cual quedó estrictamente prohibida esa doctrina y las organizaciones que pudieran desarrollarse bajo la misma. Enfatizaron su difusión al transmitirla en todos los medios escritos y editar cinco mil ejemplares. Esto sistematizó el hostigamiento y proscribió a las personas identificadas bajo el influjo de esta ideología, de tal manera que

12 "Nuevo personal nombrado en la Tipografía Nacional", Nuestro Diario, 4 de agosto de 1954: 8.

${ }^{13}$ El CDNCC tuvo jurisdicción en todo el país y se dispuso que su organigrama fuera secreto. Una de sus principales funciones fue la sistematización de los presuntos militantes comunistas durante el régimen arbencista, con lo que obtuvieron listas de hasta 70 mil nombres. Esto lo convirtió en un tribunal de las prácticas políticas de los ciudadanos. Decreto de la Junta de Gobierno 23, del 19 de julio de 1954, de la Recopilación de Leyes de Guatemala, t. LXXIII-CXLI, núm. 97, 91-1. Sustituido por el Decreto de la Junta de Gobierno 187, del 24 de diciembre de 1954, de la Recopilación de Leyes de Guatemala, t. LXXIII, 184. Con ello, se otorgaron más atribuciones al CDNCC.

14 PBHISTORY-Summary Report, Jefe del Hemisferio Occidental, 28 de septiembre de 1954, Freedom of Information Act- Electronic Reading Romm (en adelante FOIA-ERR): 0000920057, 7. 
desde el 10. de julio de 1954 iniciaron las detenciones por parte de la Guardia Civil bajo el cargo de "comunista", 15 y se recrudecieron paulatinamente, como podemos observar en los registros de la $\mathrm{CDNCC}^{16}$ y de la Policía Nacional. ${ }^{17}$

A la par de este ordenamiento legal contra los enemigos de la contrarrevolución, se consolidó la autoridad del líder liberacionista, junto a los discursos que, como veremos más adelante, tuvieron gran relevancia para la adhesión social hacia el mandatario. La implementación de un nuevo marco jurídico estableció nuevas formas de relacionarse y de participación política, bajo un cariz democrático, pese a las prácticas autoritarias que reprimieron y aniquilaron cualquier expresión de oposición o resistencia al nuevo régimen.

Fueron desarticulados los dispositivos que permitieran la organización social, con lo cual se descartaba cualquier tentativa de movilización o expresión disidente. En los siguientes años se crearon o reformularon leyes que les permitirían construir un marco institucional acorde a sus necesidades, además de facilitar la intervención en las relaciones sociales bajo estas directrices ideológicas. La Tipografía Nacional tuvo la tarea de editar las leyes que los Ministerios o Secretarías necesitaban difundir.

En 1955 fueron seis las que se publicaron bajo su sello, mientras que el Ministerio de Economía y Trabajo encargó la reproducción del Código de Petróleo y su reglamento. El siguiente año fueron 16 publicaciones, entre las cuales destacan dos, por el número de ejemplares que se hicieron: la Ley electoral, con 15 mil copias, y el Código de Trabajo, con 30 mil. En 1957 se reprodujeron ocho de ellas. El siguiente cuadro ofrece un panorama amplio de este rubro:

${ }^{15}$ El primer caso de una orden de captura se registró el 1o. de julio de 1954 contra Manuel Monroy Flores, acusado de asesinato en masa de reos anticomunistas y señalado como líder agrario en Sacatepéquez. El segundo fue contra Manuel Zúñiga, quien encabezó una delegación comunista el 22 de junio para capturar anticomunistas, y el tercero contra los líderes del Partido Guatemalteco del Trabajo. Órdenes Generales de la Guardia Civil, 1954, Guatemala, Archivo Histórico de la Policía Nacional (en adelante AHPN), GT PN 365, libro 10563, doc. 1760054, 430-431.

${ }^{16}$ En este registro se suman 2525 personas consignadas al CDNCC del 1o. de julio de 1954 a agosto de 1957. Libro especial para anotar la entrada y salida de individuos filocomunistas consignados al Comité de Defensa Nacional Contra el Comunismo, $2^{\circ}$ Cuerpo, 1954, Guatemala, AHPN, GT PN 24, libro 15966, doc. 3382950.

17 Tan sólo en 1955 registraron 951 aprehensiones. Memoria de los Trabajos Ilevados a cabo en la República por la Policía Nacional en 1955, PN, 1957, Guatemala, AHPN, GT PN 30, libro 30, doc. 52545, 72-73. 
1954 Ministerio de Gobernación. Estatuto Político de la República de Guatemala. Tipografía Nacional.

Secretaría de Propaganda y Divulgación de la Presidencia. Ley Preventiva Penal contra el Comunismo. Tipografía Nacional.

1955 Ministerio de Gobernación. Ley de Inquilinato. Decreto gubernativo número 178. Tipografía Nacional.

Ministerio de Economía y Trabajo. Código de Petróleo. Tipografía Nacional.

Ministerio de Economía y Trabajo. Reglamento del Código de Petróleo. Tipografía Nacional.

Roberto Azurdia Alvarado. Decretos y principales acuerdos emitidos desde el 3 de julio al 31 de diciembre de 1954. Tomo I. Tipografía Nacional.

Roberto Azurdía Alvarado. Decretos y principales acuerdos emitidos durante el primer trimestre del año de 1955 (enero-febrero y marzo). Tomo Il. Tipografía Nacional.

Roberto Azurdia Alvarado. Decretos y principales acuerdos emitidos durante el segundo trimestre del año de 1955 (abril, mayo y junio). Tomo III. Tipografía Nacional.

Ministerio de Economía y Trabajo. Ley de Marcas, nombres y avisos comerciales, su reglamento y clasificación. Decreto gubernativo número 882. Tipografía Nacional.

Ministerio de Economía y Trabajo. Ley de Patentes de invención. Decreto gubernativo número 2011. Tipografía Nacional.

Banco de Guatemala. Ley de Bancos. Decreto número 315. Tipografía Nacional.

Dirección General de la Policía Nacional. Ley Orgánica de la Policía Nacional. Decreto gubernativo número 332. Tipografía Nacional.

Colegio Estomatológico de Guatemala. Ley de Colegiación obligatoria para el ejercicio de las profesiones universitarias. Tipografía Nacional.

1956 Ministerio de Gobernación. Ley electoral. Decreto 1069. Tipografía Nacional.

Código de Trabajo. Tipografía Nacional.

Ministerio de Economía y Trabajo. Ley de Estadística. Decreto número 495. Tipografía Nacional.

Banco de Guatemala. Ley de Bancos de Ahorro y Préstamo para la Vivienda Familiar. Tipografía Nacional.

Ley de Espectáculos Públicos. Decreto número 574. Tipografía Nacional.

Confederación Deportiva Autónoma de Guatemala. Ley Orgánica del Deporte. Decreto número 566. Tipografía Nacional.

Ramiro Valdés V. Leyes Vigentes. Tipografía Nacional.

Ley de Orden Público. Decreto número 22. Tipografía Nacional.

Ley de Creación del Banco del Agro. Decreto número 569. Tipografía Nacional.

Ministerio de Gobernación. Ley de Vagancia. Decreto número 118. Tipografía Nacional.

Ministerio de Gobernación. Ley de Emisión del Pensamiento. Decreto número 24. Tipografía Nacional.

Presidencia de la República. Estatuto Agrario. Decreto número 559. Tipografía Nacional.

Ministerio de Gobernación. Reglamento para loterías, rifas y juegos: 18 de mayo de 1956.

Tipografía Nacional.

Contaduría General de la Nación. Instrucciones sobre inventarios de oficinas públicas. Tipografía Nacional.

Ministerio de Economía. Código de Minería. Decreto legislativo número 2000 y leyes relativas a la materia. Tipografía Nacional. 
1956 Roberto Azurdia Alvarado. Decretos y principales acuerdos emitidos durante el tercer trimestre del año de 1955 (julio, agosto y septiembre). Tomo IV. Tipografía Nacional.

Roberto Azurdia Alvarado. Decretos y principales acuerdos emitidos durante el cuarto trimestre del año de 1955 (octubre-noviembre y diciembre). Tomo V. Tipografía Nacional.

Roberto Azurdia Alvarado. Decretos y principales acuerdos emitidos durante el primer trimestre del año de 1955 (enero, febrero y marzo). Tomo VI. Tipografía Nacional.

Ministerio de Relaciones Exteriores. Se declara concluido el estado de guerra que existió con Alemania desde el 11 de diciembre de 1941. Decreto número 1127. Tipografía Nacional.

1957 Contraloría General de Cuentas. Ley Orgánica del Tribunal y Contraloría de Cuentas. Decreto número 1126. Tipografía Nacional.

Roberto Azurdia Alvarado. Decretos y principales acuerdos emitidos durante el segundo trimestre del año de 1956 (abril-mayo-junio). Tomo VII. Tipografía Nacional.

Mateo Morales Urrutia y Roberto Azurdia Alfaro. Recopilación de leyes de la República de Guatemala. Año 1947-1948. Tomo LXVI. Tipografía Nacional.

Mateo Morales Urrutia y Roberto Azurdia Alfaro. Recopilación de leyes de la República de Guatemala. Año 1948-1949. Tomo LXVII. Tipografía Nacional.

Ministerio de Economía y Trabajo. Decreto número 345. Código de Petróleo (3a. edición). Tipografía Nacional.

Consejo del Bienestar Social de Guatemala. Estatutos del Consejo del Bienestar Social de Guatemala. Tipografía Nacional.

Ministerio de Economía. Reglamento del Código de Petróleo (2a. edición). Tipografía Nacional.

Ministerio de Gobernación. Leyes de Migración de Guatemala. Tipografía Nacional.

Ministerio de Gobernación. Acuerdo regional para la importación temporal de vehículos de carretera. Decreto número 1152. Tipografía Nacional.

Presidencia de la República. Estatuto Agrario (con sus reformas). Tipografía Nacional.

Ministerio de Gobernación. Código Municipal. Decreto número 1183. Tipografía Nacional.

Bajo la misma línea se encuentra la colección del recopilador de leyes Roberto Azurdia Alfaro, encargado de ordenar los decretos de este régimen, que inician con los emitidos desde el 3 de julio de 1954 y concluyen en el segundo trimestre de 1956, en total siete tomos.

No obstante, después de la muerte de Castillo Armas, Azurdia Alfaro continuó la compilación de estos decretos hasta el segundo lustro de los años 80, durante el mandato de Vinicio Cerezo. Además, esta labor la extendió a lo realizado en gestiones anteriores, lo que junto a Mateo Morales Urrutia publicaron en dos tomos en 1957. El promedio del tiraje de cada título fue de dos mil ejemplares, sin embargo, el tomo VII de la colección fue excepcional, ya que se imprimieron 10300 copias. A este tipo de obras se suma el texto Leyes Vigentes, que Ramiro Valdés V. editó en 1956. 
El 1o. de septiembre renunciaron a la junta el coronel Monzón Aguirre y el mayor Oliva Quintana, por lo que el líder liberacionista asumió la presidencia y efectuó un plebiscito el 10 de octubre, para ratificar su puesto. Posteriormente se instaló, el 29 de octubre de ese año, una Asamblea Nacional Constituyente, en la que el Congreso Nacional presentó un proyecto de Constitución ${ }^{18}$ y se reprodujeron cinco mil copias. Finalmente, el 6 de noviembre, frente a dicha asamblea se realizó la ceremonia que dio legalidad y legitimidad al nuevo régimen. De esta manera, el 2 de febrero de 1956 fue aprobada la nueva Constitución, que entró en vigor un mes después. Por medio del Ministerio de Gobernación, cinco meses más tarde, la Tipografía Nacional publicó 10 mil ejemplares de este documento ${ }^{19}$ y el año siguiente, cuatro mil más. ${ }^{20}$ Como parte de esta categoría, es decir, en la publicación de Constituciones, y bajo el sentimiento unionista de la región, también se publicó ese año la referente a la República Federal de Centroamérica, de 1884. ${ }^{21}$

\section{b) Discursos}

Uno de los productos recurrentes en estas publicaciones fue la impresión de discursos, es decir, textos organizados para transmitir un mensaje a través de un sujeto enunciante -como acto de la oralidad-y que fueron convertidos a la escritura. Los pronunció Castillo Armas en un evento público, a excepción de dos: el primero corresponde a Luis Felipe Balcárcel, quien se dirigió a los trabajadores y campesinos el 12 de julio, al celebrarse el día del anticomunista; el segundo es del vocal de la Junta de Gobierno, coronel Monzón Aguirre, al celebrarse el día de la Unidad Nacional de las Fuerzas Armadas y el Ejército de Liberación, el 1o. de agosto de 1954 en el Campo Marte. Las 14 publicaciones restantes son reproducciones de los discursos pronunciados por Castillo Armas, los cuales inician con el mensaje que dio también el día del anticomunista, cuando aún era presidente de la Junta de Gobierno. Posteriormente, cuando ostentó la Presidencia de la República, se reprodujeron 10 discursos más y tres recopi-

\footnotetext{
${ }^{18}$ Congreso Nacional, Proyecto de Constitución de la República de Guatemala (Guatemala: Tipografía Nacional, 1955).

19 Ministerio de Gobernación, Constitución de la República de Guatemala (Guatemala: Tipografía Nacional, 1956).

${ }^{20}$ Ministerio de Gobernación, Constitución de la República y otras leyes importantes (Guatemala: Tipografía Nacional, 1956).

${ }^{21}$ Constitución de la República Federal de Centroamérica. Dada por la Asamblea Nacional Constituyente en 22 de noviembre de 1884 (Guatemala: Tipografía Nacional, 1956).
} 
laciones de dichas alocuciones, una de ellas publicada en 1955 y dos en 1957, como puede observarse en el cuadro general de estas obras:

Año Título

1954 Luis Felipe Balcárcel. Manifiesto del ciudadano Luis Felipe Balcárcel. Tipografía Nacional.

Elfego H. Monzón. Discurso del vocal de la Junta de Gobierno coronel Elfego H. Monzón en la celebración del día de "la Unidad Nacional del Ejército". Tipografía Nacional.

Carlos Castillo Armas. El Teniente Coronel Carlos Castillo Armas, Presidente de la Junta de Gobierno, se dirige al pueblo de Guatemala el 12 de julio de 1954. Tipografía Nacional.

Carlos Castillo Armas. Discurso pronunciado por el Teniente Coronel Carlos Castillo Armas en el momento de ser investido como Presidente Constitucional de la República. Tipografía Nacional.

Carlos Castillo Armas. Discurso del Presidente de la República, Teniente Coronel Carlos Castillo Armas pronunciado el 9 de octubre de 1954. Tipografía Nacional.

Carlos Castillo Armas. Mensaje del ciudadano Presidente de la República Teniente Coronel Carlos Castillo Armas a la Asamblea Nacional Constituyente al inaugurarse sus sesiones. Tipografía Nacional.

1955 Carlos Castillo Armas. Discursos pronunciados en el banquete que el honorable cuerpo diplomático acreditado en Guatemala ofreciera al señor Presidente de la República Coronel Carlos Castillo Armas el 10. de junio de 1955. Tipografía Nacional.

Carlos Castillo Armas. Discurso pronunciado por el señor Presidente de la República de Guatemala en la inauguración de la Primera Reunión de Ministros de Relaciones Exteriores de Centroamérica. Antigua Guatemala 18 de agosto de 1955. Tipografía Nacional.

1956 Carlos Castillo Armas. Mensaje del Presidente de la República, coronel Carlos Castillo Armas, al Congreso de la República, al inaugurarse el primer periodo de sus sesiones ordinarias. 10. de marzo de 1956. Tipografía Nacional.

Carlos Castillo Armas. Discurso del coronel Carlos Castillo Armas: presidente constitucional de la República, con oportunidad del segundo aniversario de la liberación, pronunciado en el Campo de Marte el 3 de julio de 1956. Tipografía Nacional.

Carlos Castillo Armas. Discurso pronunciado al suscribir la Declaración de Panamá. Tipografía Nacional.

1957 Carlos Castillo Armas. Mensaje a la mujer guatemalteca. Tipografía Nacional.

Carlos Castillo Armas. Discursos del Presidente de Guatemala. Tipografía Nacional.

Carlos Castillo Armas. Discursos del Presidente de Guatemala, coronel Carlos Castillo Armas.

Tipografía Nacional.

Carlos Castillo Armas. Discurso del presidente de la República de Guatemala coronel Carlos Castillo Armas pronunciado con motivo del III aniversario del Movimiento de Liberación Nacional. Tipografía Nacional.

Si bien los mandatarios tienen actividad pública constante, la reproducción de los discursos por medios escritos posee una relevancia política inmediata en la transmisión de sus idearios, consolidan al Estado y difunden el proyecto con el que se dirige. En el caso de Castillo Armas, coadyuvaron en el fortalecimiento de su figura como líder indiscutible del proceso liberacionista y dirigente de la construcción de una nueva sociedad y una nueva nación. 
No sólo se delimitó como antítesis del comunismo y sus representaciones, en este caso con el arbencismo y el régimen que derrocó, sino que se autorrepresentó ideológicamente. Se ajustó una comunidad política que activó la esfera pública en un circuito donde participaron los impresos de la Tipografía Nacional, la reproducción de dichas arengas en los diarios y la opinión de diversos sectores a través de los medios de comunicación; con ello, también se buscó dar legitimidad al régimen impuesto por el movimiento anticomunista, además de hacer lo propio con su gobierno frente a los ciudadanos, y de ser reconocido por sus similares a nivel internacional. ${ }^{22}$

Ejemplo de lo anterior son los discursos que pronunció, primero el 9 de octubre de 1954, próximo a los comicios electorales para formar la Asamblea Constituyente. Posteriormente, el del 1o. de junio de 1955, dirigido al cuerpo diplomático en Guatemala y, finalmente, el conmemorativo del III Aniversario del triunfo liberacionista, los cuales alcanzaron tirajes de cinco mil copias. Estos escritos corresponden a la regulación de su proyecto político, la búsqueda de reconocimiento externo a través de un acto protocolario y el énfasis del proyecto contrarrevolucionario, a escasas semanas de morir asesinado.

\section{c) Administrativos}

Frente a las regulaciones y el discurso presidencial dirigido a consumar la nueva estructura de poder político, está la planificación económica del nuevo régimen. Para ello se creó -por medio del Decreto presidencial 132, del 10. de noviembre de 1954- el Consejo Nacional de Planificación Económica, ${ }^{23}$ conformado por los ministros de Economía, Hacienda, Comunicaciones, Agricultura y Salud Pública que, junto con el presidente del Banco de Guatemala, ${ }^{24}$ tuvieron la responsabilidad de seguir el contenido del proyecto castilloarmista.

\footnotetext{
22 Ante la postura de algunos gobiernos centroamericanos, empeñados en evitar el avance del comunismo en Guatemala, el 4 de abril de 1953, el ministro de Relaciones Exteriores, Raúl Osegueda Palala, anunció la renuncia de su país a la Organización de Estados Centroamericanos (ODECA). Luego Castillo Armas designó a Adrián Recinos Ávila representante de su gobierno ante la ONU, donde, en octubre de 1954, se adhirió a la "Declaración de Caracas", la reincorporación a la ODECA, la ratificación del Tratado Interamericano de Asistencia Recíproca y de la carta de la OEA.

${ }^{23}$ Decreto presidencial 132, del 10. de noviembre de 1954, de la Recopilación de Leyes de Guatemala, t. LXXIII-CXLI, núm. 81, 140-681.

${ }^{24}$ Representado por Jorge Arenales Catalán, Jorge Echeverría Lizarralde, Martín Prado Vélez, Lázaro Chacón Pazos, Carlos Sosa Barillas y Gabriel Orellana Estrada.
} 
Fue la columna vertebral en dicha materia, aunque no deben pasarse por alto las directrices marcadas por el gobierno estadounidense, con las que se buscó explotar los recursos naturales, modernizar la infraestructura, reestructurar el problema agrario y regular las relaciones laborales, como puede verse en los mismos decretos realizados en esa gestión y en la publicación del Plan de Desarrollo Económico del cual, en la versión de 1956, sólo se imprimieron 500 ejemplares, mientras que en 1957 se produjeron 10 mil copias. ${ }^{25}$

El desarrollo de estos planes y el quehacer para modernizar al país fueron complemento para la publicidad del régimen en los años siguientes. En junio de 1956 se inició con la edición de los informes referentes al trabajo realizado, el primero de ellos sobre la gestión administrativa del mandatario liberacionis$\operatorname{ta}^{26} \mathrm{y}$, posteriormente, respecto a las obras que inauguró en el mes patrio. ${ }^{27} \mathrm{La}$ importancia de este último, a dos años de ser envestido como presidente, se reflejó en la cantidad de ejemplares, pues alcanzó los 15 mil. El siguiente año, los informes publicados se dirigieron al Congreso de la República. ${ }^{28}$

Entre los textos publicados en 1957 se encuentran las memorias de algunas dependencias. El escaso número de copias realizadas permite señalar que su objetivo era de carácter administrativo o de control interno, más allá del trabajo de difusión de los logros del gobierno, pues oscilan entre los 200 y 225 ejemplares, y son las siguientes:

Ministerio de Hacienda y Crédito Público. Memoria de las labores del Ministerio de Hacienda y Crédito Público, que comprende el año fiscal 1955-1956 y primer semestre del 1956-1957. Tipografía Nacional.

Ministerio de Gobernación. Memoria de las labores del ramo de Gobernación del 2 de julio de 1954 al 31 de diciembre de 1955. Tipografía Nacional.

Ministerio de Relaciones Exteriores. Memoria sobre la cuestión de límites entre Guatemala y México, presentada al señor Ministro de Relaciones Exteriores por el jefe de la Comisión Guatemalteca. 1900.

Tipografía Nacional.

${ }^{25}$ Carlos Castillo Armas, Plan de Desarrollo Económico de Guatemala, 1955-1960 (Guatemala: Tipografía Nacional, 1956); Consejo Nacional de Planificación Económica, Guatemala. Plan de Desarrollo Económico 1955-1956 (Guatemala: Tipografía Nacional, 1957).

${ }^{26}$ Presidencia de la República, Una era de labor constructiva (Guatemala: Tipografía Nacional, 1956).

27 Secretaría de Propaganda, Cultura y Turismo de la Presidencia, Algunas obras que el Gobierno de la Liberación inaugura con motivo de las celebraciones del CXXXV aniversario de la Independencia Patria (Guatemala: Tipografía Nacional, 1956).

${ }_{28}$ Carlos Castillo Armas, Informe del presidente de la República coronel Carlos Castillo Armas al Organismo Legislativo al inaugurarse sus sesiones ordinarias (Guatemala: Tipografía Nacional, 1957); Congreso de la República, Gigantesca obra administrativa. Enfoca y analiza el Congreso (Guatemala: Tipografía Nacional, 1957). 
Ministerio de Gobernación. Informaciones. Ministerio de Gobernación. Tipografía Nacional. Ministerio de Economía y Trabajo. Memoria de las labores realizadas durante el año 1955 por todas las dependencias de Economía y Trabajo. Tipografía Nacional.

Ministerio de Agricultura. Memoria de las labores realizadas durante el año 1955 en el Ministerio de Agricultura. Tipografía Nacional.

Ministerio de Gobernación. Memoria del Ministerio de Gobernación. Tipografía Nacional.

Como parte de estos informes se encuentra uno que, si bien no corresponde a una dependencia oficial o ministerio en específico, tiene que ver con la relación de compromiso y agradecimiento que tenía Castillo Armas con los congresos realizados por la Confederación Interamericana de Defensa del Continente, es decir, contra la Intervención Soviética en América Latina, encabezados por el almirante Carlos Penna Boto, presidente de la Cruzada Brasileña Anticomunista, y Jorge Prieto Laurens, presidente del Frente Popular Anticomunista Mexicano, ${ }^{29}$ ante el apoyo que se brindó a su campaña liberacionista en 1954. La participación de la delegación guatemalteca en ellos tuvo el aval y soporte económico de la presidencia, además de que fue un medio por el cual se transmitieron tanto la figura del coronel como los logros de su gobierno. ${ }^{30}$

Como se mencionó, el respaldo internacional que requería el nuevo régimen era apremiante. Para el presidente guatemalteco, además de posicionarse regionalmente, era indispensable mostrar que su gesta y su gobierno habían emprendido el camino correcto. Por ello, fue de gran valía la realización de la primera reunión ordinaria de cancilleres del Istmo en la ciudad de Antigua, Guatemala, del 17 al 24 de agosto de 1955. En ella, Castillo Armas retomó los intereses unionistas de los países miembros y ratificó su lucha contra el comunismo. Las resoluciones del encuentro perfilaron la defensa de la democracia y la prohibición de cualquier actividad de corte comunista, "promoviendo el intercambio de información entre gobiernos para combatir cualquier indicio de su presencia". ${ }^{31}$ Tanto las ponencias y debates durante las sesiones como el acta final del evento fueron publicadas por la Tipografía Nacional un par de meses después. ${ }^{32}$

\footnotetext{
29 Juan Carlos Vázquez Medeles, "La presencia guatemalteca en los Congresos anticomunistas latinoamericanos", Cuadernos Inter.c.a.mbio sobre Centroamérica y el Caribe, núm. 17 (2020), https://doi.org/10.15517/c.a.v17i2.41764.

${ }^{30}$ Delegación de Guatemala, Informe del III Congreso contra la Intervención Soviética en América Latina (Guatemala: Tipografía Nacional, 1957).

${ }^{31}$ Organización de Estados Centroamericanos, Reuniones y conferencias de Ministros de Relaciones Exteriores de Centroamérica. 1951-1967 (Costa Rica: Publicaciones de la Secretaría General, 1967), 51-54.

${ }^{32}$ Ministerio de Relaciones Exteriores, Actas taquigráficas de las sesiones plenarias de ministros de Relaciones Exteriores de la República Centroamericana (Guatemala: Tipografía
} 
Por otra parte, se prestó atención a dos reuniones de carácter interno. La primera corresponde a la II Reunión de gobernadores departamentales, ${ }^{33}$ y de sus memorias se tiraron dos mil ejemplares en marzo de 1957. En la segunda, el ministro de Economía, Edgar Alvarado Pinneta, presentó las mesas redondas $^{34}$ llevadas a cabo entre la iniciativa privada ${ }^{35}$ y el gobierno para fomentar la producción, plantear los asuntos patronales y los problemas fiscales, entre otros asuntos. Dicha reunión, efectuada entre el 21 y el 25 de julio de 1957, se recuerda como la última en la que participó el presidente Castillo antes de ser asesinado.

\section{d) Otros}

En este último apartado presento cinco obras que son parte del conglomerado de información, funciones administrativas y actividades de la gestión castilloarmista, pero que no corresponden a ninguno de los grupos antes abordados.

El conocimiento territorial es un elemento importante para el ejercicio de gobierno, ya que permite gestionar los recursos económicos y la planificación de la infraestructura necesaria. Con esa base, en 1954 se publicaron cinco mil copias de Departamentos, municipios, ciudades, villas, pueblos, aldeas y caseríos de la República, ${ }^{36}$ y en 1957, un número igual de ejemplares de la Guía sociogeográfica de Guatemala con referencia a las condiciones de vida, lugares de atractivo turístico y necesidades de los municipios de la República. ${ }^{37}$ Las obras

Nacional, 1955); Ministerio de Relaciones Exteriores, Acta final de la I Reunión de Ministros de Relaciones Exteriores de las Repúblicas de Centro América (Guatemala: Tipografía Nacional, 1955).

${ }_{33}$ Ministerio de Gobernación, /l Reunión de gobernadores departamentales (Guatemala: Tipografía Nacional, 1957).

${ }_{34}^{34}$ Ministerio de Economía, Mesas redondas (Guatemala: Tipografía Nacional, 1957).

${ }^{35}$ Enrique Matheu Palomo fue portavoz del Comité Coordinador, en representación de la Asociación General de Agricultores, Asociación General de Industriales, Cámaras Unidas de Comercio e Industria, Asociación de Comerciantes Guatemaltecos, Asociación Guatemalteca de Productores de Algodón y Asociación de Aceites Esenciales. Dicho comité fue el antecedente del Comité Coordinador de Asociaciones Agrícolas, Comerciales, Industriales y Financieras (CACIF), organismo que aglutinó al empresariado guatemalteco y que ha usado su poder económico para incidir en las administraciones presidenciales, desde 1957 a la fecha.

${ }^{36}$ Dirección General de Estadística, Departamentos, municipios, ciudades, villas, pueblos, aldeas y caseríos de la República (Guatemala: Tipografía Nacional, 1954).

37 Jorge del Valle, Guía sociogeográfica de Guatemala con referencia a las condiciones de vida, lugares de atractivo turístico y necesidades de los municipios de la República (Guatemala: Tipografía Nacional, 1956). 
restantes corresponden a las efemérides de la Liberación, una obra de teatro y un directorio del Consejo de Bienestar Social. ${ }^{38}$

En total, el rubro Gubernativo produjo 83 obras, 53.1\% fueron del ámbito Legislativo, $19.28 \%$ fueron Discursos y del Administrativo $21.69 \%$, como puede observarse en el siguiente cuadro.

\begin{tabular}{|c|c|c|c|c|c|c|c|}
\hline Gubernativo & 1954 & 1955 & 1956 & 1957 & \multicolumn{1}{c|}{ Total } & $\%$ \\
\hline Legislativos & 2 & 12 & 19 & 11 & $\mathbf{4 4}$ & $53.1 \%$ \\
\hline Discursos & 6 & 2 & 4 & 4 & $\mathbf{1 6}$ & $19.28 \%$ \\
\hline Administrativos & & 2 & 3 & 13 & $\mathbf{1 8}$ & $21.69 \%$ \\
\hline Otros & 1 & 1 & 2 & 1 & $\mathbf{5}$ & $6.02 \%$ \\
\hline Total & $\mathbf{8}$ & $\mathbf{1 6}$ & $\mathbf{2 6}$ & $\mathbf{2 8}$ & $\mathbf{8 3}$ & $100 \%$ \\
\hline
\end{tabular}

Libros impresos del rubro Gubernativo. Elaboración propia.

La cantidad de publicaciones bajo este carácter muestra el control burocrático y la celeridad con que se instauró el nuevo gobierno, así como las medidas desarrolladas para, en primer lugar, ejercer el poder con valores aparentemente democráticos $y$, en segundo, combatir a su enemigo político bajo un marco jurídico que legitimara su aniquilamiento. Con el propósito de concretar sus objetivos, también fue necesario convencer a la población y a la opinión internacional de que sus acciones y el camino emprendido eran correctos, para ello adaptaron las herramientas existentes y explotaron los conocimientos previos con el fin de difundir su mensaje, como se verá en la siguiente categoría.

\section{Rubro Propagandístico}

En este segundo rubro presentaré cinco tipos de obras que funcionaron como publicidad del régimen castilloarmista: a) Monográficos; b) Literarios; c) Gráficos; d) Históricos y, e) Otros. Estas obras tuvieron amplia circulación y fueron elaboradas inmediatamente después de que Castillo Armas asumiera el poder.

${ }^{38}$ Secretaría de Difusión, Cultura y Turismo, Efemérides de la Liberación. Junio y julio de 1954 (Guatemala: Tipografía Nacional, 1955); Alberto Martínez, Alberto Martínez presenta por vigésimo año consecutivo, la obra cumbre de la Asociación Dramática Nacional "Don Juan Tenorio" (Guatemala: Tipografía Nacional, 1956); Consejo del Bienestar Social, Directorio de Instituciones Miembros del Consejo de Bienestar Social (Guatemala: Tipografía Nacional, 1957). 
Sus características se complementan con el primer rubro, pese a las diferencias sustanciales de su composición, como veremos a continuación.

\section{a) Monográficos}

La necesidad de transmitir un proyecto de gobierno se tradujo en la elaboración de diversos textos en calidad de soporte material y simbólico de su concepción sobre la historia y la realidad, su autorrepresentación comunitaria y la proyección de ideas, es decir, fueron constructores de ideologemas. Estas publicaciones se impusieron como voces autorizadas que pretendían legitimar el poder que se ejercía y sistematizaron estos elementos culturales y socio-políticos para identificarse como grupo. La autoría de estos textos fue de diversa índole, en algunos se asume de manera individual, mientras que en otros o carece de autor o corresponde a un grupo específico que se autoidentifica o se intuye por la composición y contenido de la obra.

Uno de sus detalles sobresalientes es el uso de la imagen desde la portada. En este sentido, la mayoría de ellos rompe con el repertorio de la póliza tipográfica utilizada en el Rubro Gubernativo, donde sólo se dispuso el texto a una tinta (negra) y excepcionalmente se incluía la azul. Y con cuatro elementos descendentes: a) Entidad responsable; b) Título; c) Autor; d) Lugar y año de publicación.

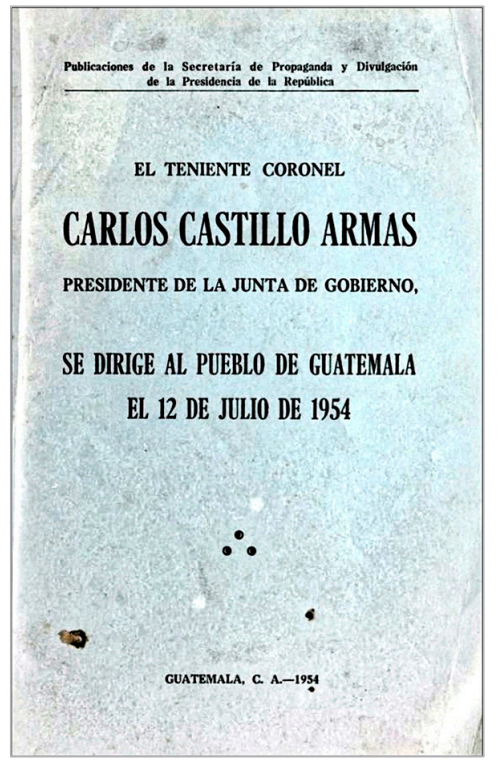

Imagen 1. Ejemplo de portadas correspondientes al Rubro Gubernativo. Carlos Castillo Armas.

El Teniente coronel Carlos Castillo Armas. Presidente de la Junta de Gobierno, se dirige al pueblo de Guatemala el 12 de julio de 1954

(Guatemala: Tipografía Nacional, 1954). 
La variación en la tipometría se acentuó cuando incorporaron paráfrasis, que disminuyeron su medida para acoplar el espacio al aumento de letras. Los elementos decorativos incluyeron viñetas $u$ ornamentos tipográficos sutiles a un solo clisé (flor, punto, asterisco), o un grabado calcográfico de determinados escudos institucionales. Las ediciones de lujo se presentaron en pasta dura con el título, el escudo nacional, lugar y año de publicación en dorado, además de una imagen a golpe seco.

En el conjunto que ahora presento el dibujo armonizó con la textualidad y la portada actuó como una pieza comunicante. Los ilustradores de la Tipografía Nacional sintetizaron las ideas y conceptos que pretendían transmitir con una paleta de colores básica en la que sobresalían el rojo, el negro, el azul y el amarillo. Al mismo tiempo, se introdujeron múltiples fotografías a manera de ilustración y documentos como pruebas fehacientes del valor de verdad de su narración. Su estridencia material se debe a su concepción como producto propagandístico del régimen, que se difundiría tanto al interior del país como en el exterior. En general, su contenido configuró un discurso histórico autorreferencial, antagónico a los gobiernos anteriores. Las imágenes utilizadas en la portada de algunos de estos libros muestran la ruptura con las tendencias artísticas que emergieron en los gobiernos revolucionarios, principalmente con la pintura y el grabado.

Imagen 2. Ejemplo de portadas correspondientes al Rubro Propagandístico. Luis Alberto Hurtado Aguilar. Así se gestó la Liberación (Guatemala: Tipografía Nacional, 1956).

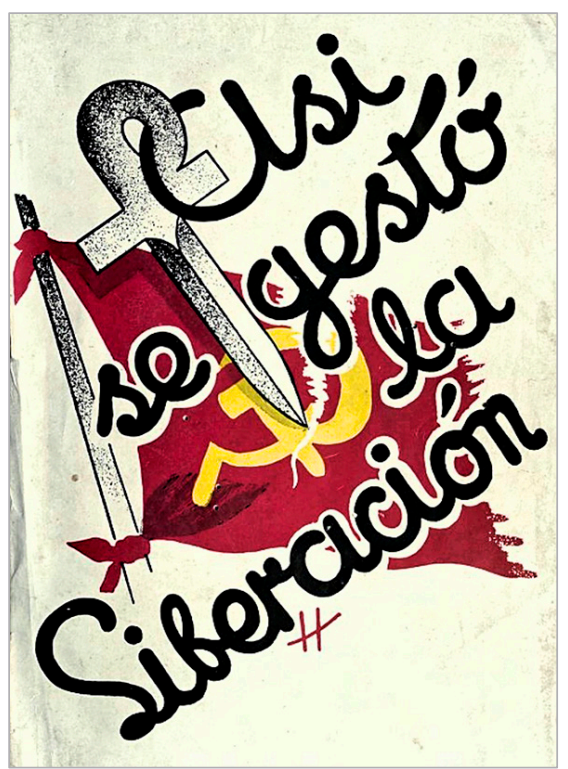


En los años previos, la efervescencia cultural aglutinó a los artistas en diversos colectivos, algunos de ellos abrazaron los ideales y proyectos políticos que se configuraron a partir de la Revolución de Octubre de 1944. Si bien el desarrollo de la técnica en el grabado tuvo su propio camino, la confluencia de extranjeros en Guatemala permitió consolidar el compromiso político de los artífices.

En 1951, la Escuela Nacional de Artes Plásticas abrió la clase de Grabado con el dibujante español Jesús Matamoros Llopis ${ }^{39}$ como maestro y se contrató al grabador mexicano Arturo García Bustos, quién fundó en la misma institución, un año después, el Taller Libre de Grabado, donde confluyeron jóvenes creadores y miembros de agrupaciones culturales como Saker-Ti y la Asociación Guatemalteca de Estudiantes y Artistas Revolucionarios (AGEAR), empeñados en la búsqueda de un lenguaje estético popular que reivindicara las características revolucionarias. Además, se pretendía que a través de la gráfica se estableciera una comunicación inmediata y de fuerte impacto en una población con altos índices de analfabetismo.

El nuevo régimen desmanteló este proceso artístico y cultural a partir de decretos ${ }^{40} \mathrm{y}$, como hemos mencionado, distintos elementos creativos ligados a la Secretaría de Divulgación y Propagada y de la Tipografía Nacional fueron remplazados o marginados. ${ }^{41}$ Quienes conformaron el nuevo grupo de trabajo

${ }^{39}$ Matamoros Llopis fue de los republicanos españoles que llegaron a Guatemala durante los gobiernos de Arévalo y Árbenz. Su experiencia como dibujante lo llevó a trabajar en la Escuela Nacional de Artes Plásticas y en la Secretaría de Divulgación y Propaganda de la Presidencia. También fue redactor en el Diario de la Mañana. Al hacerse del poder el Movimiento de Liberación Nacional, se asiló en la Embajada de México junto con sus compatriotas. Algunos de ellos también trabajaron en la SDyP, como el escritor y militante del Partido Comunista Español, Fernando Fernández Revuelta y su hijo José Fernández Doris, quienes obtuvieron salvoconductos, tanto para ellos como para sus familiares (Purificación González G. de Fernández, Alba Fernández González, Dinora Fernández Doris, Aída Nazoa de Fernández Doris y Nora Fernández Nazoa). Lista de personas asiladas en la sede de la Embajada de México a las que se ha concedido salvo-conducto por el gobierno de Guatemala, Archivo Histórico Genaro Estrada, Secretaría de Relaciones Exteriores (en adelante AHGE-SRE), México, B1-135-4, 2-4.

${ }^{40}$ En septiembre se suspendieron las actividades de la Escuela Nacional de Artes Plásticas: Decreto presidencial 66, de septiembre de 1954, de la Recopilación de Leyes de Guatemala, t. LXXIII, 81.

${ }^{41}$ Algunos buscaron asilo en la embajada mexicana después de la invasión liberacionista, entre ellos: el cubano Armando Francisco Santa Cruz López, dibujante en la campaña presidencial de Árbenz y cercano a la SDCyT; Carlos González Orellana, secretario de Propaganda de la Presidencia; el periodista dominicano y asilado político Pericles Franco Hornes, redactor de la SDCyT; el periodista Augusto Enrique Noriega, redactor de prensa 
crearon una estética diferente, apartada de los ideologemas revolucionarios. Si bien menoscabó su calidad, expresó los símbolos del régimen y el rechazo al comunismo, que difundieron como plataforma política.

En general, los contenidos de las obras de este rubro abordaron cuatro tópicos:

1. Demostrar que los gobiernos de los expresidentes Arévalo y Árbenz eran comunistas.

2. Que el comunismo en Guatemala era parte de una conjura internacional y el Partido Guatemalteco del Trabajo se infiltró en el gobierno.

3. Que los comunistas cometieron crímenes de lesa humanidad y genocidio, lo cual llevó a Guatemala al colapso. En tanto que el liberacionismo impartirá una verdadera justicia. Con relación a estos tres primeros puntos, se presentan listas de presuntos comunistas y organizaciones señaladas de ostentar esta ideología.

4. Que el coronel Castillo Armas y el Ejército de Liberación Nacional salvaron a Guatemala, y su proyecto de nación construirá una democracia acorde a las condiciones del país.

En diciembre de 1954 ya circulaban cuatro textos con estas características. El primero de ellos titulado Un pueblo que se redime, del abogado Jorge del Valle Matheu, ministro de Educación Pública, quien declaró en los medios que se proyectaba la realización de una historia imparcial. ${ }^{42}$ Dos más estuvieron suscritos a la Secretaría de Propaganda y Divulgación, uno impreso en la Tipografía Nacional: La barbarie comunista en Guatemala; y otro en la Imprenta Iberia: ${ }^{43} \mathrm{La}$ intriga roja. La portada de este último es la única firmada, obra de Carlos Rigain, quien no destacó como artista plástico en la escena cultural, pero sobresalió

en la SDCyT, en el Diario de Centroamérica y Nuestro Diario; Raúl Leyva Muñoz, jefe de prensa de la Secretaría de Propaganda de la Presidencia, al igual que los mencionados Matamoros Llopis, Fernández Revueltas y Fernández Doris, entre otros. Ver Lista de personas asiladas en la sede de la Embajada de México en Guatemala, AHGE-SRE, 2-5.

42 "El ministro Jorge del V. Matheu a favor de una historia imparcial", La Hora, 2 de septiembre de 1954: 1.

${ }^{43}$ El dueño tanto de lberia como de la Imprenta Hispania fue Alfonso Rodríguez Muñoz, de origen mexicano y quien fungió como cónsul general de la República Española durante el gobierno de Juan José Arévalo. Además, fue inversionista en la fundación del periódico Prensa Libre, en agosto de 1951, el cual funcionó como un medio de oposición del presidente Jacobo Árbenz. 
diseñando anuncios publicitarios en materia turística y como grabador en el Taller Nacional de Grabado en Acero, adscrito a la Tipografía Nacional.

Bajo las directrices mencionadas, al asumir el poder, los liberacionistas anunciaron la publicación de un Libro Rojo, "en el cual se den a conocer todas las atrocidades cometidas por los elementos del partido comunista en Guatemala en connivencia con elementos entroncados en el gobierno y al servicio de su causa"; ${ }^{44}$ integrarían en él fotografías, artículos y reportajes de la prensa. Con estas particularidades se produjeron tres libros que se ajustan a las características señaladas, a manera de ideosemas.

La triada se compone de obras publicadas con un año de diferencia, la primera se terminó de imprimir el 16 de diciembre de 1954 y se tituló Genocidio sobre Guatemala, con el subtítulo de "Exposición del monstruoso crimen cometido contra el pueblo de Guatemala, durante los últimos días del gobierno comunista, presidido por Jacobo Árbenz derrotado por la conciencia nacional y gracias al Ejército de Liberación comandando por el CORONEL CARLOS CASTILLO ARMAS". Allí citan los artículos II, III y IV de la Convención para la prevención y la sanción del delito de Genocidio de las Naciones Unidas, para después intentar demostrar el exterminio masivo de NO COMUNISTAS y el uso de la tortura durante el gobierno que denominan árbenz-comunismo. ${ }^{45}$ Presenta testimonios orales, notas periodísticas y un amplio corpus de fotografías de víctimas, recortes de periódicos, victimarios y cadáveres de exhumaciones. ${ }^{46}$ Las atrocidades narradas y el recurso gráfico ensalzan la participación heroica de la Oposición Organizada, de la cual glorifica los nombres de sus mártires, en tanto que señala a los responsables directos de dichos crímenes, quienes no sólo son extensión de los deseos de Árbenz Guzmán, sino que participan en la planificación del genocidio, como el director de la Guardia Civil, coronel Rogelio Cruz Wer, y el director de la Guardia Judicial, coronel Jaime Rosemberg Rivera. ${ }^{47}$

44 "Libro rojo contendrá los crímenes del comunismo", La Hora, 8 de julio de 1954: 1, 8.

${ }^{45}$ En octubre de 1954 se tipificó el delito de Genocidio para llevar a tribunales varios casos. "Calificado en Guatemala el Delito de Genocidio", El Espectador, 18 de octubre de 1954: 1, 4.

46 Julio Adolfo Rey señala que "es imposible decir si estas imágenes fueron tomadas en realidad por Rosemberg o fueron fabricadas por el régimen liberacionista con fines de propaganda". Julio Adolfo Rey, "Revolution and Liberation: A Review of Recent Literature on the Guatemalan Situation", The Hispanic American Historical Review 38, núm. 2: 250.

${ }^{47}$ Fueron acusados del delito de genocidio por el auditor de guerra, el licenciado Bernardo Vides Menéndez. Además de los mencionados, se señaló a: Miguel Ángel Duque 
El siguiente año, el 30 de junio de 1955, se publicó El calvario de Guatemala, subtitulado "Publicación del Comité de Estudiantes Universitarios Anticomunistas en el primer aniversario del Movimiento de Liberación Nacional. 3 de Julio de 1954 - 3 de Julio de 1955". Se exhibe como "documento probatorio definitivo de cómo y porqué fue mancillado el pueblo de Guatemala" y presenta una apología de la participación del CEUA en la lucha liberacionista. Inicia con una réplica a La Batalla de Guatemala ${ }^{48}$ del excanciller Guillermo Toriello, quien expuso la intromisión extranjera que destituyó al régimen democrático arbencista. Este recurso de impugnación fue utilizado con frecuencia en estas publicaciones para menoscabar el impacto que estas obras ocasionaban. De esta manera, trataron de minimizar la denuncia o exposición de las argucias diplomáticas y militares que utilizó el Ejército de Liberación para hacerse del poder.

El 6 de junio de 1956, la tercera de estas obras empezó a circular: Así se gestó la Liberación..$^{49}$ En ese momento la imagen de su caudillo estaba asentada con firmeza, por lo que el protagonismo de su narración pasó de los supuestos crímenes del comunismo - sin suprimirlos-a la configuración de su lucha como la gesta que salvó a Guatemala. El texto ofrece una larga lista de liberacionistas, con nombre, seudónimo y el cargo que ocuparon durante la invasión de junio de 1954, además de otros documentos y actividades que realizaron durante su organización, tanto en el interior del país como en el exilio. Los temas son recurrentes, así como el uso de documentos y fotografías, que varían poco entre ellos y de los que hablaré más adelante. Su tiraje fue de cinco mil ejemplares, pero El calvario de Guatemala tuvo una segunda edición en la cual se alcanzaron 15 mil unidades en total.

Los tópicos abordados coinciden con el Álbum de la contrarrevolución, ${ }^{50}$ documento resguardado en el Archivo Histórico del Centro de Investigaciones

Salguero, Raúl Dubon Garzona, Alfonso Martínez Estéves, Marco Tulio Torres, Ramiro Carrillo Bobadilla, Reginaldo Archila Adquí, Antonio Bojorquez, Adalberto Santos Galindo, Arturo Morales Oliva y Felipe Zepeda Bermúdez.

${ }^{48}$ Guillermo Toriello, La Batalla de Guatemala, Cuadernos Americanos 39 (México: UNAM, 1955).

${ }^{49}$ Existe un título similar, pero publicado con 20 años de diferencia, a manera de homenaje, y contiene rasgos testimoniales de su autor. Ver Guillermo Putzeys, Así se hizo la Liberación (Guatemala: Tipografía Nacional, 1976).

${ }^{50}$ El documento es un álbum de 22 × 14 pulgadas, con 177 páginas que contienen recortes de periódicos, fotografías, cartas y otros objetos. Álbum de la contrarrevolución, Guatemala, Archivo Histórico del Centro de Investigaciones Regionales de Mesoamérica, Archivo Histórico, núm. 21 (GT-CIRMA-AH-021). 
Regionales de Mesoamérica desde octubre de 2001. Fue donado por Enrique Matheu Recinos, ${ }^{51}$ quien lo obtuvo de su pariente político Thelma Chacón, esposa de John Mario Willensen Devlin, todos cercanos al gobierno liberacionista. La primera página contiene por ambos lados la disposición de su contenido: "Las mentiras del Árbenz-comunismo", "Genocidio", "Torturas y vejámenes", "Comunismo desenmascarado", "Asilados", "Liberación", "Pacto San Salvador", "Junta de Gobierno", "Ejército de Liberación", "2 de agosto", "Castillo Armas presidente", "Notas personales", "Monseñor Rossell", "Arana", "Prensa extranjera", "Chistes y Bromas", "Discos" y "Libro Blanco". Además, ostenta las firmas autógrafas de los protagonistas destacados en el Movimiento de Liberación, y de su consolidación en el poder. ${ }^{52}$ La información que contiene permite observar la disposición de los temas de interés público y cómo siguieron las pautas desde las publicaciones de la Tipografía Nacional y los propios medios de comunicación.

De los 14 libros restantes editados en el periodo estudiado, los contrastes en los estilos y formas de narrar variaron en la temática abordada. La más recurrente fue la que se ciñó al agro guatemalteco, ya que, además de ser un pilar de su proyecto económico, enfrentó la política en este tema impulsada por el régimen anterior. Junto a ello, se impulsó el proyecto de alfabetización y educativo en las zonas rurales, que presentaron como parte de la planificación del régimen castilloarmista, pero que en realidad retomaron de sus predecesores. El resto de las obras fue el siguiente:

\begin{tabular}{|c|c|}
\hline Año & Título \\
\hline \multirow[t]{4}{*}{1954} & Jorge del Valle. Un pueblo que se redime. (Páginas de la Liberación). Tipografía Naci \\
\hline & $\begin{array}{l}\text { Secretaría de Divulgación, Cultura y Turismo. La barbarie comunista en Guatemala... } \\
\text { and Other Articles. Tipografía Nacional. }\end{array}$ \\
\hline & Secretaría de Divulgación y Propaganda. La intriga roja en Guatemala. Imprenta Iberia. \\
\hline & Secretaría de Propaganda y Divulgación. Genocidio sobre Guatemala. Tipografía Nacional. \\
\hline \multirow[t]{3}{*}{1955} & $\begin{array}{l}\text { Secretaría de Divulgación, Cultura y Turismo. El libro blanco de Jacobo Árbenz Guzmán. } \\
\text { Tipografía Nacional. }\end{array}$ \\
\hline & $\begin{array}{l}\text { Comité de Estudiantes Universitarios Anticomunistas. El calvario de Guatemala. } \\
\text { Tipografía Nacional. }\end{array}$ \\
\hline & Héctor Alfonso Leal. Tierra de Liberación para el Campesino. Tipografía Nacional. \\
\hline
\end{tabular}

${ }^{51}$ Su padre, Enrique Recinos Palomo, fue representante de las mesas redondas entre la iniciativa privada y Castillo Armas en julio de 1957.

52 Las firmas son de Enrique Oliva, Mario Sandoval Alarcón, Lionel Sisniega Otero, Dario Soto M., Domingo Goicolea, Armando Sandoval, Óscar Cobar, Eduardo Taracena, Luis Valladares y Aycinema, Enrique Salazar Lieckens, Rodolfo Reholht, José Torón Barrios, José Calderón Salazar y Odilia de Castillo. 
1956 Carlos María Campos Jiménez. Organización y desarrollo de la comunidad por el bienestar social. Tipografía Nacional.

Luis Alberto Hurtado Aguilar. Así se gestó la Liberación. Tipografía Nacional. Guatemala: lo que opina América sobre el país de la eterna primavera, 1956. Imprenta Real.

Secretaría de Divulgación, Cultura y Turismo. Historia de un golpe rojo. L.A.H.A. [El Gobierno de la República informó acerca del origen y desarrollo de los acontecimientos políticos de junio de este año]. Imprenta Iberia.

1957 Presidencia de la República. Nueva Vida. Tipografía Nacional.

Luis Coronado Lira. El jardín de los suplicios. Tipografía Nacional.

Carlos Castillo Armas. Prólogo de Mario Efraín Nájera Farfán. La realidad de un mensaje: pláticas presidenciales. Tipografía Nacional.

León de Gandarias. Democracia, la mejor arma contra el comunismo. Tipografía Nacional.

Secretaría de Difusión y Turismo. La verdad sobre la última conspiración sobre el comunismo. Tipografía Nacional.

Presidencia de la República. Guatemala y su dolor: corona fúnebre sobre la tumba del coronel Carlos Castillo Armas. Tipografía Nacional.

Alicia Mayorga de Palarea. Estudio del contenido de las mesas redondas panamericanas que durante su periodo presidencial, hiciera como medio de propaganda. Tipografía Nacional.

Rafael Cardona. El Hombre, la Tierra y el Alfabeto en Guatemala. Tipografía Nacional.

Gerardo Guinea. Armas para ganar una batalla. Tipografía Nacional.

Departamento Agrario Nacional. Desarrollo Agrario en marcha. Tipografía Nacional.

\section{b) Literarios}

En este rubro se editaron siete obras y sólo una de ellas -en sus dos tomos- se ajusta a los contenidos que he presentado. Por esta razón y su estilo destaco Letras de la Liberación ${ }^{53}$ del periodista y exdirigente del Comité de Exiliados Guatemaltecos Anticomunistas en México, José Calderón Salazar. En 1955, con tan sólo unos meses de diferencia y un tiraje de dos mil copias por tomo, el autor presentó diversos fragmentos que se transmitieron por la Radio Nacional de Guatemala al celebrarse el primer aniversario de la contrarrevolución. Comprende la plataforma ideológica de los liberacionistas, sus mártires, símbolos y deseos, reseñados con gran habilidad literaria para dotar su "cruzada" de heroicidad y misticismo. La lírica utilizada, por el miembro de Acción Católica y colaborador de la Falange española en Guatemala, sustituyó los recursos visuales que fueron utilizados en las obras monográficas. Al año siguiente, se publicó la experiencia de Carlos E. Arana durante los años democráticos para denunciar

53 José Calderón Salazar, Letras de la Liberación, t. I y || (Guatemala: Tipografía Nacional, 1955). 
al comunismo. ${ }^{54}$ No obstante, las siguientes obras se enfocaron en impulsar la poesía ${ }^{55}$ y rememorar la imagen de los Chapines de ayer. ${ }^{56}$

\section{c) Gráficos}

Estas publicaciones se ligaron a los objetivos propagandísticos de la operación PBHISTORY, que pretendía transmitir el alcance de la penetración comunista, además de demostrar "la verdad de las representaciones hechas previamente por el gobierno de Estados Unidos ${ }^{\prime \prime 5}$ y las atrocidades reseñadas a través de sus agencias o las tácticas utilizadas por un Estado bajo esta ideología, por lo que el régimen castilloarmista serviría como punto de proyección para el resto de Latinoamérica. Destinaron camarógrafos y fotógrafos para producir imágenes -fijas y en movimiento- que utilizaron en la difusión de sus propósitos; según ellos, sus documentos: "desenmascararían gráficamente a los ex líderes como comunistas y expondrían hasta qué punto los comunistas habían controlado el gobierno de Árbenz". ${ }^{58}$

Este trabajo estaba dirigido por personal de PBHISTORY, quienes prepararon versiones en inglés y español para que el ministro de la SDCYT, Enrique Salazar Lieckens, difundiera las imágenes en el interior y exterior de Guatemala, en 90 periódicos de distintos países. ${ }^{59}$ El proyecto se complementó con la presentación de un video titulado "Después supimos la verdad" y "kits de propaganda compuestos por copias fotostáticas de documentos, ejemplo de propaganda soviética enviada a Guatemala y atroces fotografías". ${ }^{60}$ Algunas de ellas -como lo indica un reporte de la CIA- con palabras en ruso y matasellos de Moscú, pósteres de Stalin, Mao, Lenin, Malenkov y Árbenz, y aprehensiones de comunistas. ${ }^{61}$

${ }^{54}$ Carlos E. Arana, En ruta hacia la muerte (Guatemala: Tipografía Nacional,1956).

${ }^{55}$ Rafael Arévalo Martínez, El Hijo Pródigo (Guatemala: Tipografía Nacional, 1956); Asociación Nacional Cívica Cultural, Poemario. (Poetas jóvenes guatemaltecos) (Guatemala: Tipografía Nacional, 1957); Héctor Guillermo Pineda, Canto lluminado (Guatemala: Tipografía Nacional, 1957).

${ }^{56}$ Carlos Samayoa Chinchilla, Chapines de ayer (Guatemala: Tipografía Nacional, 1957).

${ }^{57}$ Report on Actions Taken by the U. S. Information Agency in the Guatemala Situation, Operations Coordinating Board, 2 de agosto de 1954, FOIA-ERR, doc. núm. CIA-RDP80R0 1731R003000030004-6.

${ }^{58}$ PBHISTORY (W/Attachment), Director de la Central de Inteligencia, 11 de enero de 1955, FOIA-ERR, doc. núm. 0000920013.

59 Release Sent out by Guatemalan Ministry of Propaganda, 7 de septiembre de 1954, FOIA-ERR, doc. núm. 0000920089.

60 PBHISTORY (W/Attachment).

${ }^{61}$ PBHISTORY, Progress Report 4-9 August, 9 de agosto de 1954, FOIA-ERR, doc. núm. 0000920168. 
La diferencia entre este tipo y el Monográfico fue que la imagen destacó del texto y actuó como herramienta principal, por ejemplo los panfletos titulados Tres mentiras de Guatemala ${ }^{62}$ y Ellos hablaron de paz, ${ }^{63}$ sin embargo, en algunos casos sólo fueron las estampas las que se publicaron. Ejemplo de ello son los seis cuadernillos preparados por la Secretaría de Propaganda y Difusión de la Presidencia, editados en 1954 por la Imprenta Gutenberg, del escritor Jesús María Ordóñez: 64

Secretaría de Propaganda y Difusión. Documentos que la historia de Guatemala conservará para
asignarle a cada quien el lugar que justamente le corresponde. Imprenta Gutenberg.
Secretaría de Propaganda y Difusión. El Cuarto poder en funciones con el grandioso marco de la
Verdad cumpliendo una de las aspiraciones de la gesta de Liberación. Imprenta Gutenberg.
Secretaría de Propaganda y Difusión. Liberación: con sangre, sacrificio y heroísmo se escribió la historia
de nuestra segunda independencia. Imprenta Gutenberg.
Secretaría de Propaganda y Difusión. Después supimos la verdad. Imprenta Gutenberg.
Secretaría de Propaganda y Difusión. La voz del pueblo aclama al jefe del Movimiento de Liberación
Nacional, Carlos Castillo Armas. Imprenta Gutenberg.
Secretaría de Propaganda y Difusión. Nuestro Pueblo - derramó lágrimas-: al conocer el látigo y el
crimen de la "justicia" comunista en Guatemala. Imprenta Gutenberg.

Estas publicaciones se componen de entre 20 y 75 fotografías, algunas de ellas registradas por los periodistas John B. Nieder Mott de la Revista Time, Mario Ribas Montes de United Press y Jules Dubois del Chicago Tribune. Tenían perforaciones punteadas para facilitar su corte, de manera que cada hoja se convertía en una postal, además de incluir un texto que pedía que fueran divulgadas en los medios de información. Lo anterior explica la repetición constante de dichas ilustraciones, tanto en las publicaciones de la Tipografía Nacional como en la prensa local y extranjera. El pragmatismo conferido a estos materiales dificultó su conservación, por ello son pocos los ejemplares que aún se resguardan en algunos acervos bibliográficos. Su función divulgativa causó la fragmentación de su contenido y su deterioro.

\footnotetext{
${ }^{62}$ Secretaría de Divulgación y Propaganda de la Junta de Gobierno, Tres mentiras comunistas sobre Guatemala (Guatemala: Tipografía Nacional, 1954).

${ }^{63}$ Secretaría de Propaganda y Divulgación de la Presidencia de la República, Ellos hablaron de paz (Guatemala: Tipografía Nacional, 1954).

${ }^{64}$ En sus talleres, ubicados en la 6a. avenida 15-70 de la capital, se imprimió El Rebelde. Órgano de Publicidad del Comité de Estudiantes Universitarios Anticomunistas, El Manifiesto del coronel Carlos Castillo Armas y la Pastoral del arzobispo Mariano Rossell y Arellano, que sirvieron en la lucha contra el gobierno arbencista.
} 


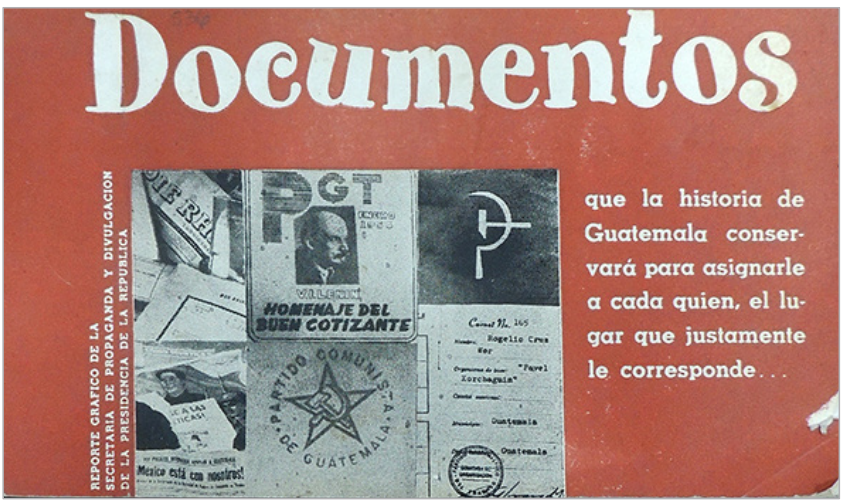

Imagen 3. Cuadernillo que muestra algunas de las imágenes que explotó el régimen castilloarmista. Secretaría de Propaganda y Difusión, Documentos que la historia de Guatemala conservará para asignarle a cada quien el lugar que justamente le corresponde (Guatemala: Imprenta Gutenberg, 1954).

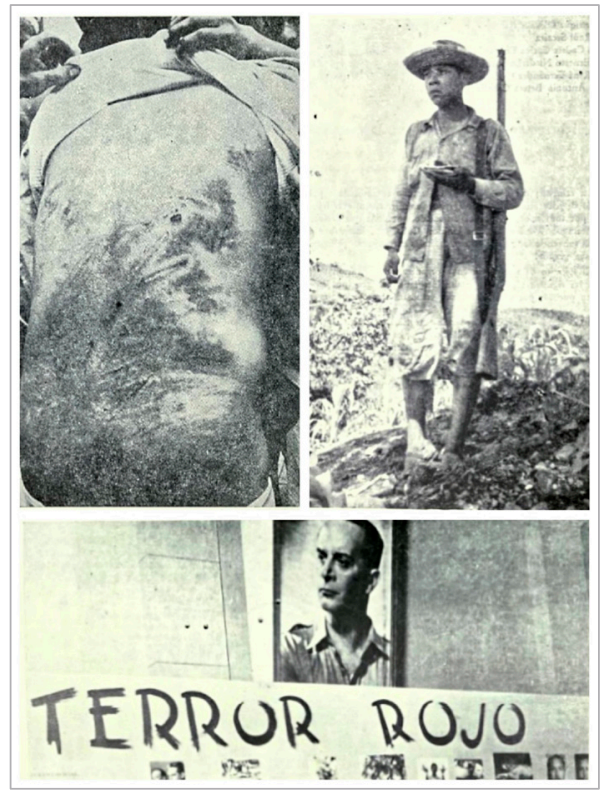

Imagen 4. Fotografías incluidas en distintas publicaciones de la Tipografía Nacional. Comité de Estudiantes Universitarios Anticomunistas, El calvario de Guatemala

(Guatemala: Tipografía Nacional, 1955), 342; Luis Alberto Hurtado Aguilar, Así se gestó la Liberación (Guatemala: Tipografía Nacional, 1956), 108, 239. 
Las imágenes abarcaron distintos temas que les interesaba difundir, incluida documentación y literatura presuntamente encontrada en las oficinas de gobierno, con las que intentaban demostrar la relación del gobierno arbencista con la Unión Soviética. Otro tópico de interés fue la exaltación de la figura de Castillo Armas y de los liberacionistas en acción, a la par de los personajes que consideraron mártires de su lucha. Lo más recurrente fue la publicación de fotografías sensacionalistas dirigidas a evidenciar el carácter criminal de los comunistas. En ellas se captaron cadáveres, secuelas de torturas y los sitios donde se cometían dichos actos de violencia contra los anticomunistas y opositores al gobierno.

Los dos libros restantes se enfocaron en difundir el viaje del presidente Castillo Armas a Estados Unidos, del 31 de octubre al 13 de noviembre de 1955. Trazan su itinerario entre varias ciudades de ese país y las reuniones que tuvo con diferentes personalidades, como el presidente Dwight D. Eisenhower, el vicepresidente Richard M. Nixon, el presidente de la OEA José Antonio Mora, el subsecretario de Estado Herbert Hoover jr. y el cardenal de Nueva York Francis Spellman. Las fotografías son de Julio César Anzueto, quien trabajó en la Secretaría de Propaganda desde el gobierno de Árbenz y logró conservar su puesto después de la intervención. Las imágenes se intercalan entre ambas obras, la primera a manera de folleto, mientras que la segunda reproduce más de cien estampas. ${ }^{65}$

\section{d) Históricos}

El fomento del pasado del país reflejó los intereses unionistas del régimen, así como la promoción de valores basados en una identidad indígena. Sin embargo, son limitadas las obras que se publicaron desde los talleres de la Tipografía Nacional. La decena de títulos -frente al conjunto de textos que tienen relación con su historia reciente y el establecimiento del nuevo régimen- quedaron relegados, tanto a su difusión como a su impacto. La relación de estas obras es la siguiente:

65 Julio César Anzueto, Guatemala y Estados Unidos, un viaje memorable, dos pueblos amigos a través de la cámara de Julio César Anzueto [desfile fotográfico del viaje del presidente coronel Carlos Castillo Armas a Estados Unidos de Norteamérica, 31 de octubre - 13 de noviembre] (Guatemala: Tipografía Nacional, 1955). Julio César Anzueto y Carlos Castillo Armas, Dos pueblos amigos. Presentación gráfica del viaje del Presidente de Guatemala coronel Carlos Castillo Armas, a los Estados Unidos de Norteamérica por invitación del Presidente de la nación general Dwight Eisenhower, del 31 de octubre al 13 de noviembre de 1955; y texto de los más importantes discursos pronunciados con ese motivo, fotos de Julio César Anzueto (Guatemala: Tipografía Nacional, 1956). 
1954 Pedro Bosch Gimpera. Historia de Oriente. Tomos / y ll. Tipografía Nacional. Antonio Batres Jáuregui. La América Central ante la Historia. 1821-1921. Tipografía Nacional.

1955 Ricardo Castañeda Paganini. Las ruinas de Palenque. Su descubrimiento y primeras exploraciones en el siglo XVIII. Tipografía Nacional.

Libertad 15 de septiembre de 1821. Tipografía Nacional.

1956 Gustavo Alemán Bolaños. Centenario de la Guerra Nacional de Nicaragua contra Walker. Costa Rica, Guatemala, El Salvador y Honduras en la Contienda. Tipografía Nacional.

José Rodríguez Cerna. Centroamérica en el Congreso de Bolívar. Contribución documental. Inédita, para la historia de la Primera Asamblea Americana. Tipografía Nacional.

José García de la Concepción. Historia Belemítica. Vida ejemplar y admirable del venerable siervo de Dios, y padre Pedro de San José Betancur, fundador de el regular Instituto de Belén. (Biblioteca Goathemala de la Sociedad de Geografía e Historia. Volumen XIX). Tipografía Nacional.

Ricardo Castañeda Paganini. Tecún Umán. Héroe nacional de Guatemala. Tipografía Nacional.

Pedro Pérez Valenzuela. Santo Tomás de Castilla. Apuntes para la historia de las colonizaciones en la costa atlántica. Tipografía Nacional.

Rolando Tejeda Padilla. Insignias patrias de Guatemala: su origen y su significado. Tipografía Nacional.

\section{e) Otros}

El último subrubro contiene obras que se alejan de las directrices señaladas; en su mayoría son textos de carácter didáctico, algunas de ellas para aprender variantes del idioma maya usado en Guatemala, ${ }^{66}$ tesis de profesionistas, ${ }^{67}$ impulso al turismo y dos textos más. ${ }^{68}$ Es particularmente interesante el relacionado con la Asociación de Scouts, ${ }^{69}$ pues se impulsó este movimiento desde la mencionada primera reunión ordinaria de los ministros de Relaciones Exteriores efectuada en Antigua, Guatemala, en agosto de 1955, donde se consideró que

${ }^{66}$ Gonzalo Vargas S., Cartilla de Alfabetización "Nuevo Día” (Guatemala: Tipografía Nacional, 1955); Guillermo Sedat S., Nuevo diccionario de las lenguas K'ekchi' y española (Guatemala: Tipografía Nacional, 1955); Alfredo Herbruger jr. y Eduardo Díaz Barrios, Método para aprender a hablar y escribir la lengua cakchiquel (Guatemala: Tipografía Nacional, 1956).

${ }^{67}$ Augusto Dardón, Hernia Lumbar de Disco Intervertebral. Su diagnóstico y tratamiento quirúrgico (Guatemala: Tipografía Nacional, 1954); Bernardo Vides, Introducción al estudio del Derecho Penal guatemalteco (Guatemala: Tipografía Nacional, 1954).

68 Guatemala National Tourist Bureau, Guatemala. The Land of Enchantment and Color (Guatemala: Tipografía Nacional, 1955); Héctor Ovidio Rodas, Mayor ética en el uso de Marcas de Comercio (Guatemala: Tipografía Nacional, 1956); Programa de la celebración del CXXXVI aniversario de nuestra independencia. 15 de septiembre de 1957.

${ }^{69}$ Asociación de Scouts de Guatemala, El adiestramiento de la Asociación de Scouters de Guatemala (Guatemala: Tipografía Nacional, 1955). 
el escultismo contribuía al acercamiento entre las juventudes de la región. ${ }^{70}$ Por su parte, Castillo Armas señaló que los scouts se ligaban a su simbología, puesto que sus principios, "Dios, Patria y Hogar", eran prácticamente los mismos que él perseguía.

En total, el Rubro Propagandístico produjo 57 obras, de las cuales $36.84 \%$ se enfocaron en la línea Monográfica, mientras que las 4 restantes no rebasaron 18\%, como se muestra a continuación:

\begin{tabular}{|ccccccc|}
\hline Propagandístico & $\mathbf{1 9 5 4}$ & $\mathbf{1 9 5 5}$ & $\mathbf{1 9 5 6}$ & $\mathbf{1 9 5 7}$ & Total & $\%$ \\
\hline Monográficos & 4 & 3 & 4 & 10 & $\mathbf{2 1}$ & $36.84 \%$ \\
\hline Literarios & & 2 & 2 & 3 & $\mathbf{7}$ & $12.28 \%$ \\
\hline Gráficos & 8 & 1 & 1 & & $\mathbf{1 0}$ & $17.54 \%$ \\
\hline Históricos & 2 & 2 & 6 & & $\mathbf{1 0}$ & $17.54 \%$ \\
\hline Otros & 1 & 5 & 2 & 1 & $\mathbf{9}$ & $15.79 \%$ \\
\hline Total & $\mathbf{1 4}$ & $\mathbf{1 3}$ & $\mathbf{1 5}$ & $\mathbf{1 4}$ & $\mathbf{5 6}$ & $100 \%$ \\
\hline
\end{tabular}

Libros impresos del Rubro Propagandístico. Elaboración propia.

En general, se elaboraron 140 publicaciones, 59.29\% en lo Gubernativo y $40.71 \%$ en lo Propagandístico. Lo que permite ver el interés de Castillo Armas por regular el marco jurídico y político del nuevo régimen, además de ubicar a Guatemala y el movimiento liberacionista como los bastiones de la lucha anticomunista en el continente. El esfuerzo de la Secretaría de Divulgación, Cultura y Turismo de la Presidencia de la República y su secretario, Enrique Salazar Liekens, fue de dimensiones extraordinarias, tanto en la edición de estas obras como en su difusión dentro y fuera del país. Los talleres de la Tipografía Nacional fueron parte integral de los recursos materiales que dieron forma a la cultura impresa de esta labor.

$\overline{70}$ Organización de Estados Centroamericanos, Reuniones y conferencias, 60. 


\section{Conclusiones}

Las publicaciones de la Tipografía Nacional contienen la plataforma políticoideológica y el marco jurídico del liberacionismo. Revelan la capacidad de producción de sus talleres, que publicaron un promedio de cuatro títulos por mes durante tres años, y más de un millón de ejemplares, con una inversión que supera los 100 mil doláres. Como medio de propaganda, permitió al gobierno de Castillo Armas glorificar su lucha anti-arbencista y encumbrar la figura del líder. Un esfuerzo que fue acompañado por diversos autores latinoamericanos, y las obras fueron distribuidas por la Agencia Central de Inteligencia.

Como antípoda de los gobiernos revolucionarios, la producción escrita rechazó cualquier concomitancia con ellos, por lo que estas publicaciones configuraron formas propias, tanto discursivas como estéticas. Las 140 obras publicadas no tienen parangón, pues no existe mandatario que supere la edición de discursos, leyes y obras referentes a su administración, como los editados por la Tipografía Nacional entre 1954 y 1957. Si bien en la década de 1960 inició el desarrollo de la contrainsurgencia en Guatemala, estos libros se presentan como los precursores del sustento ideológico del anticomunismo guatemalteco, que lo dotaron de símbolos, perspectivas políticas y memoria.

Los datos vertidos proporcionan la dimensión del proyecto cultural del castilloarmismo, que evidencia la importancia dada a la escritura y la potencia del libro como objeto utilitario en la lucha ideológica, donde la misma Tipografía Nacional funcionó como maquinaria de combate. Son el vestigio material de su ascenso y consolidación en el poder. Muestran las particularidades del país y reafirman sus interconexiones en el escenario regional y global durante el desarrollo de la Guerra Fría, en el que participan Estados, organismos internacionales y sujetos que dinamizan la evolución de la política continental, en la cual el gobierno guatemalteco pretendió encabezar el combate al comunismo, mostrarse como el baluarte de la democracia en América Latina y ser el aliado por excelencia de Estados Unidos. 


\section{Referencias}

Álbum de la contrarrevolución. Guatemala. Archivo Histórico del Centro de Investigaciones Regionales de Mesoamérica. GT-CIRMA-AH-021.

Anzueto, Julio César. Guatemala y Estados Unidos, un viaje memorable, dos pueblos amigos a través de la cámara de Julio César Anzueto [desfile fotográfico del viaje del presidente coronel Carlos Castillo Armas a Estados Unidos de Norteamérica, 31 de octubre - 13 de noviembre]. Guatemala: Tipografía Nacional, 1955.

Anzueto, Julio César y Carlos Castillo Armas. Dos pueblos amigos. Presentación gráfica del viaje del Presidente de Guatemala coronel Carlos Castillo Armas, a los Estados Unidos de Norteamérica por invitación del Presidente de la nación general Dwight Eisenhower, del 31 de octubre al 13 de noviembre de 1955; $y$ texto de los más importantes discursos pronunciados con ese motivo. Fotos de Julio César Anzueto. Guatemala: Tipografía Nacional, 1956.

Arana, Carlos E. En ruta hacia la muerte. Guatemala: Tipografía Nacional, 1956.

Arévalo Martínez, Rafael. El Hijo Pródigo. Guatemala: Tipografía Nacional, 1956.

Asociación Nacional Cívica Cultural. Poemario. (Poetas jóvenes guatemaltecos). Guatemala: Tipografía Nacional, 1957.

Asociación de Scouts de Guatemala. El adiestramiento de la Asociación de Scouters de Guatemala. Guatemala: Tipografía Nacional, 1955.

Calderón Salazar, José. Letras de la Liberación. Tomos I y II. Guatemala: Tipografía Nacional, 1955.

"Calificado en Guatemala el Delito de Genocidio". El Espectador, 18 de octubre de 1954: 1, 4.

Castillo Armas, Carlos. Informe del presidente de la República coronel Carlos Castillo Armas al Organismo Legislativo al inaugurarse sus sesiones ordinarias. Guatemala: Tipografía Nacional, 1957.

Castillo Armas, Carlos. Plan de Desarrollo Económico de Guatemala, 1955-1960. Guatemala: Tipografía Nacional, 1956.

Congreso Nacional. Proyecto de Constitución de la República de Guatemala. Guatemala: Tipografía Nacional, 1955.

Congreso de la República. Gigantesca obra administrativa. Enfoca y analiza el Congreso. Guatemala: Tipografía Nacional, 1957.

Consejo del Bienestar Social. Directorio de Instituciones Miembros del Consejo de Bienestar Social. Guatemala: Tipografía Nacional, 1957. 
Consejo Nacional de Planificación Económica. Guatemala. Plan de Desarrollo Económico 1955-1956. Guatemala: Tipografía Nacional, 1957.

Constitución de la República Federal de Centroamérica. Dada por la Asamblea Nacional Constituyente en 22 de noviembre de 1884. Guatemala: Tipografía Nacional, 1956.

Cros, Edmond. Ideosemas y morfogénesis del texto. Literaturas española e hispanoamericana. Fráncfort: Vervuert Verlag, 1992.

Cros, Edmond. La sociocrítica. Madrid: Arco Libros / La Muralla, 2009.

Dardón, Augusto. Hernia Lumbar de Disco Intervertebral. Su diagnóstico y tratamiento quirúrgico. Guatemala: Tipografía Nacional, 1954.

Decreto 224, del 4 de febrero de 1955. Recopilación de Leyes. Tomo 73, 206.

Decreto de la Junta de Gobierno 23, del 19 de julio de 1954. Recopilación de Leyes de Guatemala. Tomos LXXIII-CXLI, núm. 97, 66-945.

Decreto de la Junta de Gobierno 187, del 24 de diciembre de 1954. Recopilación de Leyes de Guatemala. Tomo LXXIII, 184.

Decreto presidencial 66, de septiembre de 1954. Recopilación de Leyes de Guatemala. Tomo LXXIII, 81.

Decreto presidencial 132, del 10. de noviembre de 1954. Recopilación de Leyes de Guatemala. Tomos LXXIII-CXLI, núm. 81, 140-681.

Delegación de Guatemala. Informe del III Congreso contra la Intervención Soviética en América Latina. Guatemala: Tipografía Nacional, 1957.

Dirección General de Estadística. Departamentos, municipios, ciudades, villas, pueblos, aldeas y caseríos de la República. Guatemala: Tipografía Nacional, 1954.

Guatemala National Tourist Bureau. Guatemala. The Land of Enchantment and Color. Guatemala: Tipografía Nacional, 1955.

Herbruger jr., Alfredo y Eduardo Díaz Barrios. Método para aprender a hablar y escribir la lengua cakchiquel. Guatemala: Tipografía Nacional, 1956.

Libro especial para anotar la entrada y salidas de individuos filocomunistas consignados al Comité de Defensa Nacional Contra el Comunismo, $2^{\circ}$ Cuerpo, 1954. Guatemala, AHPN, GT PN 24, libro 15966, doc. 3382950.

"Libro rojo contendrá los crímenes del comunismo". La Hora, 8 de julio de 1954. Lista de personas asiladas en la sede de la Embajada de México a las que se ha concedido salvo-conducto por el gobierno de Guatemala. Archivo Histórico Genaro Estrada, Secretaría de Relaciones Exteriores, México, B1-135-4, 2-4. 
Martínez, Alberto. Alberto Martínez presenta por vigésimo año consecutivo, la obra cumbre de la Asociación Dramática Nacional "Don Juan Tenorio". Guatemala: Tipografía Nacional, 1956.

Memoria de los Trabajos Ilevados a cabo en la República por la Policía Nacional en 1955. PN, 1957. Guatemala, Archivo Histórico de la Policía Nacional, GT PN 30, libro 30, doc. 52545, 72-73.

Ministerio de Economía. Mesas redondas. Guatemala: Tipografía Nacional, 1957. Ministerio de Gobernación. II Reunión de gobernadores departamentales. Guatemala: Tipografía Nacional, 1957.

Ministerio de Gobernación. Constitución de la República de Guatemala. Guatemala: Tipografía Nacional, 1956.

Ministerio de Gobernación. Constitución de la República y otras leyes importantes. Guatemala: Tipografía Nacional, 1956.

Ministerio de Gobernación. Memoria de las labores del ramo de Gobernación del 2 de julio de 1954 al 31 de diciembre de 1955. Guatemala: Tipografía Nacional, 1957.

Ministerio de Relaciones Exteriores. Acta final de la I Reunión de Ministros de Relaciones Exteriores de las Repúblicas de Centro América. Guatemala: Tipografía Nacional, 1955.

Ministerio de Relaciones Exteriores. Actas taquigráficas de las sesiones plenarias de ministros de Relaciones Exteriores de la República Centroamericana. Guatemala: Tipografía Nacional, 1955.

"El ministro Jorge del V. Matheu a favor de una historia imparcial". La Hora, 2 de septiembre de 1954.

"Nuevo personal nombrado en la Tipografía Nacional". Nuestro Diario, 4 de agosto de 1954.

Órdenes Generales de la Guardia Civil, 1954. Guatemala, Archivo Histórico de la Policía Nacional, GT PN 365, libro 10563, doc. 1760054, 430-431.

Organización de Estados Centroamericanos (ODECA). Reuniones y conferencias de Ministros de Relaciones Exteriores de Centroamérica. 1951-1967. Costa Rica: Publicaciones de la Secretaría General, 1967.

PBHISTORY, Progress Report 4-9 August, 9 de agosto de 1954. FOIA-ERR, doc. núm. 0000920168.

PBHISTORY-Summary Report. Jefe del Hemisferio Occidental, 28 de septiembre de 1954. FOIA-ERR: 0000920057, 7.

PBHISTORY (W/Attachment). Director de la Central de Inteligencia, 11 de enero de 1955. FOIA-ERR, doc. núm. 0000920013. 
Pineda, Héctor Guillermo. Canto Iluminado. Guatemala: Tipografía Nacional, 1957.

Presidencia de la República. Una era de labor constructiva. Guatemala: Tipografía Nacional, 1956.

Putzeys, Guillermo. Así se hizo la Liberación. Guatemala: Tipografía Nacional, 1976.

Release Sent Out by Guatemalan Ministry of Propaganda, 7 de septiembre de 1954. FOIA-ER, doc. núm. 0000920089.

Report on Actions Taken by the U. S. Information Agency in the Guatemala Situation. Operations Coordinating Board, 2 de agosto de 1954. FOIA-ERR, doc. núm. CIA-RDP80R01731R003000030004-6.

Rey, Julio Adolfo. "Revolution and Liberation: A Review of Recent Literature on the Guatemalan Situation". The Hispanic American Historical Review 38, núm. 2.

Rodas, Héctor Ovidio. Mayor ética en el uso de Marcas de Comercio. Guatemala: Tipografía Nacional, 1956.

Samayoa Chinchilla, Carlos. Chapines de ayer. Guatemala: Tipografía Nacional, 1957.

Secretaría de Difusión, Cultura y Turismo. Efemérides de la Liberación. Junio y julio de 1954. Guatemala: Tipografía Nacional, 1955.

Secretaría de Divulgación y Propaganda de la Junta de Gobierno. Tres mentiras comunistas sobre Guatemala. Guatemala: Tipografía Nacional, 1954.

Secretaría de Propaganda, Cultura y Turismo de la Presidencia. Algunas obras que el Gobierno de la Liberación inaugura con motivo de las celebraciones del CXXXV aniversario de la Independencia Patria. Guatemala: Tipografía Nacional, 1956.

Secretaría de Propaganda y Divulgación de la Presidencia de la República. Ellos hablaron de paz. Guatemala: Tipografía Nacional, 1954.

Sedat S., Guillermo. Nuevo diccionario de las lenguas K'ekchi' y española. Guatemala: Tipografía Nacional, 1955.

Taracena, Arturo. Guatemala, la República Española y el Gobierno Vasco en el exilio (1944-1954). México: El Colegio de México, 2017.

Toriello, Guillermo. La Batalla de Guatemala. Cuadernos Americanos 39. México: Universidad Nacional Autónoma de México, 1955.

Valle, Jorge del. Guía sociogeográfica de Guatemala con referencia a las condiciones de vida, lugares de atractivo turístico y necesidades de los municipios de la República. Guatemala: Tipografía Nacional, 1956. 
Vargas S., Gonzalo. Cartilla de Alfabetización "Nuevo Día". Guatemala: Tipografía Nacional, 1955.

Vázquez Medeles, Juan Carlos. "La presencia guatemalteca en los Congresos anticomunistas latinoamericanos". Cuadernos Inter.c.a.mbio sobre Centroamérica y el Caribe, núm. 17 (2020). https://doi.org/10.15517/c.a. v17i2.41764.

Vides, Bernardo. Introducción al estudio del Derecho Penal guatemalteco. Guatemala: Tipografía Nacional, 1954. $\mathrm{bg}$ 